ENRICO FERMI ATOMIC POWER PLANT NUCLEAR TEST SERIES

APDA - NTS - 5

\title{
MEASUREMENT OF THE ISOTHERMAL TEMPERATURE COEFFICIENT OF REACTIVITY OF THE ENRICO FERMI REACTOR
}

by

\author{
H. A. Wilber \\ E. A. Fischer \\ R. E. Mueller
}

\section{ATOMIC POWER DEVELOPMENT ASSOCIATES, INC.}




\section{DISCLAIMER}

This report was prepared as an account of work sponsored by an agency of the United States Government. Neither the United States Government nor any agency Thereof, nor any of their employees, makes any warranty, express or implied, or assumes any legal liability or responsibility for the accuracy, completeness, or usefulness of any information, apparatus, product, or process disclosed, or represents that its use would not infringe privately owned rights. Reference herein to any specific commercial product, process, or service by trade name, trademark, manufacturer, or otherwise does not necessarily constitute or imply its endorsement, recommendation, or favoring by the United States Government or any agency thereof. The views and opinions of authors expressed herein do not necessarily state or reflect those of the United States Government or any agency thereof. 


\section{DISCLAIMER}

Portions of this document may be illegible in electronic image products. Images are produced from the best available original document. 


\section{FOREWORD}

This report is one of a series of reports on the low-power (up to $1 \mathrm{Mwt}$ ) and high-power (up to $200 \mathrm{Mwt}$ ) nuclear testing of the Enrico Fermi fast breeder reactor. The Nuclear Test Program is planned, directed, and evaluated by Atomic Power Development Associates, Inc. (APDA). The tests are conducted by Power Development Company (PRDC). The reactor proper is owned and operated by PRDC. The steam generators and electrical generation facilities are owned by The Detroit Edison Company (DECo).

Many people have contributed to the success of the nuclear testing of the Enrico Fermi reactor. Listed below are the names of those people, exclusive of the authors, who made significant contributions to some phase of the work reported in this document.

APDA

C. E. Branyan

R. E. Horne
PRDC

E. L. Alexanderson

W. R. Olson

J. D. Herb

G. C. Tyson
DECo

F. J. Locke

J. A. Nyquist 
TABLE OF CONTENTS

$\underline{\text { Page }}$

LIST OF ILLUSTRATIONS . . . . . . . . . . . . . . . . . . . . . . 5

LIST OF TABLES ......................... . . . . . . .

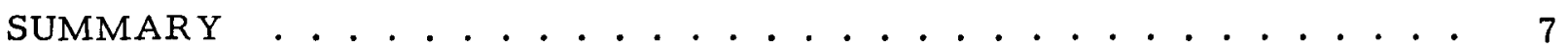

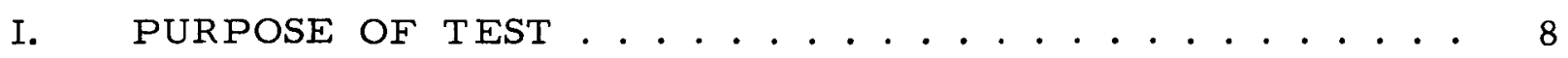

II. DESCRIPTION OF THE ENRICO FERMI REACTOR AND

ITS TEMPERATURE EFFECTS .............. . . 9

A. GENERAL DESCRIPTION OF THE REACTOR ..... 9

B. TEMPERATURE EFFECTS IN THE REACTOR . . . . . 12

C. PREDICTED VALUE OF THE ISOTHERMAL
TEMPERATURE COEFFICIENT . . . . . . . . . 13

III. EXPERIMENTAL PROCEDURE ................ 18

A. DESCRIPTION OF TEST ............... 18

1. Measurement Over the Temperature Range

$400 \mathrm{~F}$ to $520 \mathrm{~F}$................. 18

2. Measurements Over the Temperature Range

$500 \mathrm{~F}$ to $540 \mathrm{~F}$.................... 18

3. Measurements Over the Temperature Range $400 \mathrm{~F}$ to $600 \mathrm{~F}$................. 20

B. REACTOR FUEL LOADINGS AND PLANT CONDITIONS . . 23

C. INSTRUMENTATION .............. 27

1. Nuclear Instrumentation ............. 27

2. Temperature Sensing Instrumentation ........ 28

3. Rod Position Instrumentation ........... 28

4. Miscellaneous Plant Instrumentation . . . . . . . 30

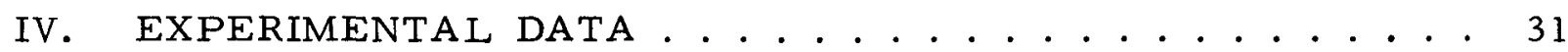

V. MATHEMATICAL ANALYSIS OF THE DATA AND EXPERIMENTAL RESULTS . . . . . . . . . . . . . 34

A. DETERMINATION OF THE ISOTHERMAL

TEMPERATURE COEFFICIENT ............ . 34

1. First Set of Measurements . . . . . . . . . . . . 34

2. Second and Third Sets of Measurements . . . . . . 35

a. Analysis of the Critical Rod Data . . . . . . 35

b. Analysis of the Positive Period Data . . . . . 38 
TABLE OF CONTENTS (Continued)

$\underline{\text { Page }}$

3. Error Analysis .................. 45

B. DETERMINATION OF THE GROWTH OF THE CONTROL ROD EXTENSIONS ............. 46

VI. DATA REDUCTION ...................... . . . . 47

A. AVERAGE ISOTHERMAL TEMPERATURE

COEFFICIENT VALUES . . . . . . . . . . . . . . . . . 47

B. EXPERIMENTAL EQUATION FOR THE ISOTHERMAL

TEMPERATURE COEFFICIENT . . . . . . . . . . . . 48

C. STANDARD ERROR OF THE MEASUREMENTS FROM

THE EXPERIMENTAL DATA ............ 50

VII. CONCLUSIONS ..................... 53

REFERENCES ...................... 54 


\section{LIST OF ILLUSTRATIONS}

Figure

Title

$\underline{\text { Page }}$

1 Perspective View of Reactor ................ 10

2 Reactor Cross Section .................. 11

3 Variation of Thermal Expansion Coefficients with

Temperature .................... 16

4 Core Loading for the First Measurement . . . . . . . . . 24

5 Core Loading for the Second Measurement . . . . . . . 25

6 Core Loading for the Third Measurement . . . . . . . . 26

7 Location of Neutron Guide Tubes in Graphite Shield . . . . . . 29

8 Excess Reactivity versus Critical Regulating Rod Position . . 36

9 Excess Reactivity versus Critical Shim Rod Position . . . . 37

10 Reactivity versus Reactor Period . . . . . . . . . . 41

11 Isothermal Temperature Coefficient versus Temperature . . 51 


\section{LIST OF TABLES}

Table

Title

$\underline{\text { Page }}$

I. Predicted Isothermal Temperature Coefficient of Reactivity .

II. Critical Rod Data from the First Measurement . . . . . . 31

III. Critical Rod Data from the Second and Third Measurements . 32

IV. Positive Period Data from the Second and Third Measurements ................. 33

V. Isothermal Temperature Coefficients from Critical Rod Position Data .. . . . . . . . . . . . . . . . .

VI. Delayed and Prompt Neutron Data for the Fermi Reactor . . . 40

VII. Isothermal Temperature Coefficients from One-Period Data . 43

VIII. Isothermal Temperature Coefficients from Two-Period Data . 44

* IX. Values of the Average Isothermal Temperature Coefficients . 47

X. Least Square Data ................... 49

XI. Standard Error Tabulation ............... . 52 
SUMMAR Y

The isothermal temperature coefficient of reactivity of the Enrico Fermi reactor was measured for various reasons on three different occasions during the reactor low-power nuclear test program. It was first measured on September 3 and 4, 1963, concurrent with the absolute power calibration measurements. From these measurements, an average isothermal temperature coefficient of $-0.83 \mathrm{ih} / \mathrm{F}$ over the temperature range $400 \mathrm{~F}$ to $520 \mathrm{~F}$ was obtained. The next determination was made during the period October 16 to 18,1963 . These measurements were made over the narrow temperature range $500 \mathrm{~F}$ to $540 \mathrm{~F}$ and yielded a value of $-0.84 \mathrm{ih} / \mathrm{F}$. The third set of temperature coefficient measurements was made during the period November 8 to 16,1963 . These were detailed measurements made over the temperature range $400 \mathrm{~F}$ to $600 \mathrm{~F}$ in $40 \mathrm{~F}$ increments. The magnitude of the temperature coefficient varied from $-0.8436 \mathrm{ih} / \mathrm{F}$ at the ave rage temperature of the lower temperature increment of the test $(420 \mathrm{~F})$ to $-0.8665 \mathrm{ih} / \mathrm{F}$ at the average temperature of the upper temperature increment $(580 \mathrm{~F})$. During this portion of the test, it was also possible to measure, mechanically, the thermal expansion of the operating control rod drive extensions. The average expansion of the extensions was measured to be $+0.0003 \mathrm{inch} / \mathrm{F}$ over the temperature range of $400 \mathrm{~F}$ to $600 \mathrm{~F}$.

The agreement between the measured and calculated values of the isothermal temperature coefficient of reactivity is considered satisfactory. The measured values are, on the average, about 7 per cent smaller than predicted. Because the calculations involved in the predictions are quite complex, a discrepancy larger than this would not have been unexpected. From the good agreement, it appears that the method used for calculating temperaturereactivity feedback effects in the reactor is probably accurate. This gives reason for optimism that the calculated power coefficients will also be sufficiently accurate. 


\section{PURPOSE OF TEST}

Each of the three measurements of the isothermal temperature coefficient of reactivity (ITCR) that were made in the Enrico Fermi reactor served a different purpose.

The first measurement was made at the beginning of the nuclear test program, over the temperature range $400 \mathrm{~F}$ to $520 \mathrm{~F}$, to establish a preliminary indication of its magnitude. If the measured value had been grossly different from the predicted value, subsequent procedures in the test program would have been re-evaluated.

The second measurement of the isothermal temperature coefficient was made to obtain values that could be used in making reactivity corrections for minor temperature variations in the primary system during subsequent tests. The narrow temperature range investigated, $500 \mathrm{~F}$ to $540 \mathrm{~F}$, bracketed the temperatures used for the majority of the low-power tests.

The third and last measurement was made to confirm reactor design data pertaining to temperature over ride reactivity requirements. In this part of the test, the temperature coefficient was measured between $400 \mathrm{~F}$ and $600 \mathrm{~F}$ at $40 \mathrm{~F}$ intervals. This broad range bracketed the reactor refueling temperature, $517 \mathrm{~F}$, and established whether any unexpected variation in the temperature coefficient occurred with temperature. The value of the temperature coefficient at refueling temperature is important because it is used in determining the reactivity effect of changes in the primary sodium coolant inlet temperature during an approach to power. The data from the third set of measurements could also be compared to the predicted data to obtain an indication of the accuracy of the calculational method used for temperature-reactivity feedback studies in the design of the reactor. Therefore, the data gave a preliminary indication of the accuracy of the power coefficient of reactivity predictions. Because of the wide range of temperature variation used in this portion of the test, it was also possible to measure the thermal expansion of the operating control rods and their extensions. With this information, the effect of temperature on the rod calibration curves could be determined. 


\section{DESCRIPTION OF THE ENRICO FERMI REACTOR AND ITS TEMPERATURE EFFECTS}

\section{A. GENERAL DESCRIPTION OF THE REACTOR}

The Fermi reactor and its associated structures are shown in perspective in Figure 1. The reactor is contained in a stainless steel reactor vessel sealed at the top by a rotating shield plug which supports the control mechanisms, the fuel subassembly hold-down mechanism and the subassembly handling mechanism. The reactor is of the fast-breeder type, cooled by sodium, and is operated at essentially atmospheric pressure. The maximum reactor power obtainable with the first core loading (Core A) is $200 \mathrm{Mwt}$.

The core and blanket are located in the lower reactor vessel and consist of 2.646-square-inch subassemblies containing the fuel pins and blanket rods. The core and blanket subassemblies are arranged to approximate a cylinder about 80 inches in diameter and 70 inches high. The core, which is contained in the central portion of the core subassemblies, approximates a right cylinder 31 inches in diameter and 31 inches high; it is axially and radially surrounded by breeder blankets. The fuel in the first core loading consists of zirconium-clad pins, 0.158 inch in diameter, containing U- 10 w/o molybdenum alloy in which the uranium is enriched to $25.6 \mathrm{w} / \mathrm{o}$ in U-235. Each fuel subassembly in the core contains 140 fuel pins for a total mass of approximately 4.75 kilograms of U-235 per subassembly. The inner and outer radial blanket subassemblies each contain twenty-five 0.443 -inchdiameter blanket rods of depleted U-3 w/o molybdenum alloy.

The reactor cross section, shown in Figure 2, indicates the placement of individual components within the lower reactor vessel. There is a total of 149 central lattice positions that are occupied by core and inner radial blanket subassemblies, the antimony-beryllium ( $\mathrm{Sb}-\mathrm{Be}$ ) neutron source, and the 10 operating control and safety rod channels. All of these positions are supplied with sodium coolant flowing upwards from a high-pressure plenum which is connected to the discharge lines of the three primary sodium pumps. The coolant flows upward through the individual core and inner radial blanket subassemblies and into a large upper plenum. From there it flows by gravity to the three intermediate heat exchangers and then to the suction side of the primary pumps. Sodium also is used in the secondary cooling system.

The lattice positions surrounding the inner radial blanket contain the outer radial blanket subassemblies. Beyond the outer radial blanket are lattice positions used for stainless steel filled thermal shield bar subassemblies. These subassemblies provide thermal and neutron shielding for the 


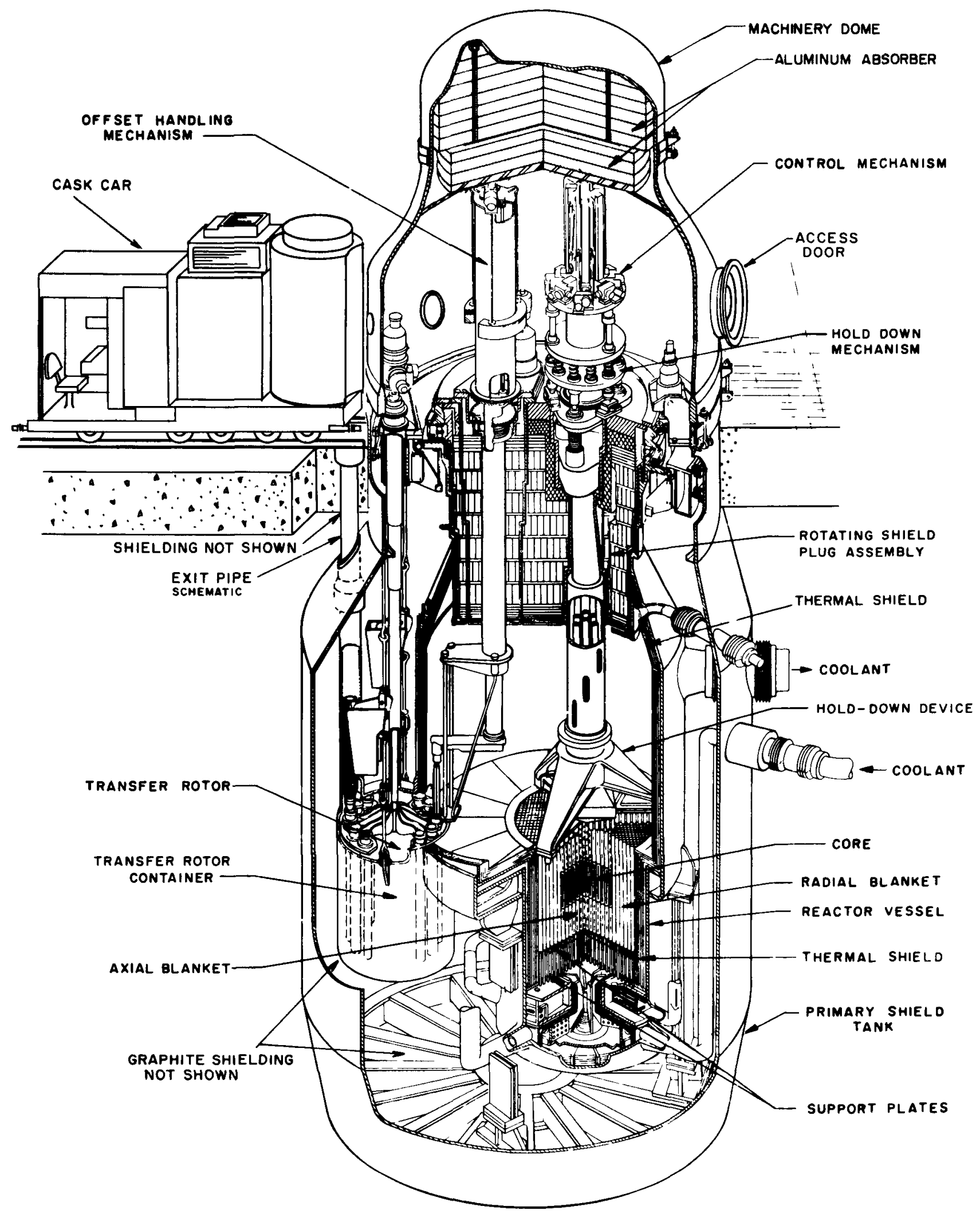

FIG. I - PERSPECTIVE VIEW OF REACTOR 


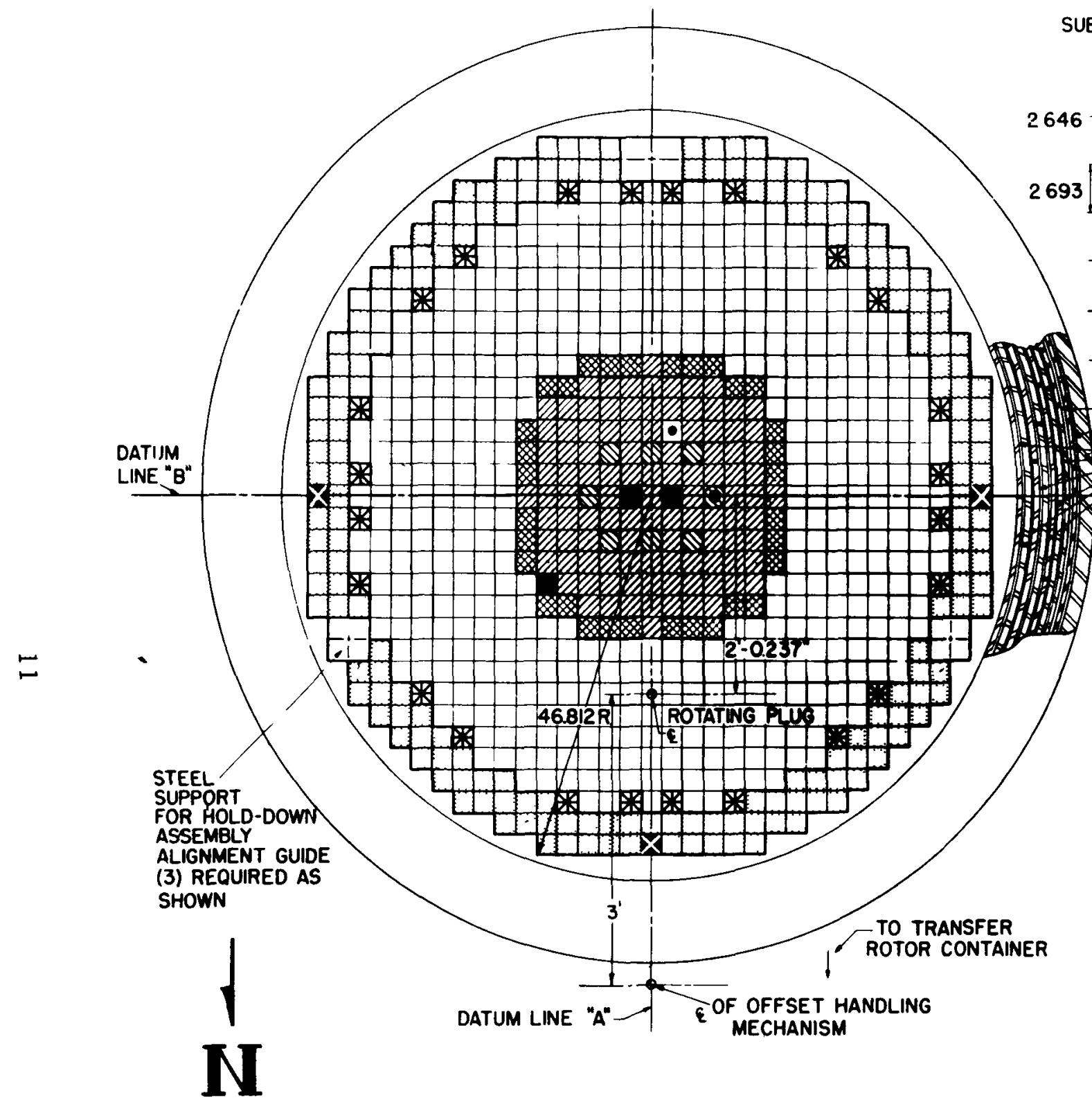

ARRANGEMENT

$2693 \quad 047$

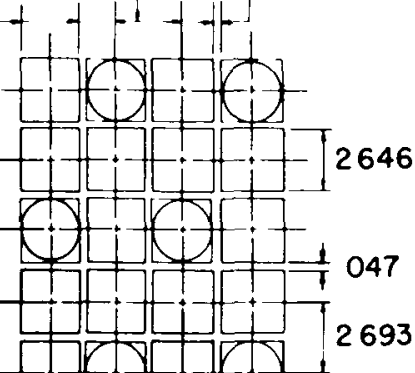

THERMAL BAFFLES

THERMAL SHIELO INSTALLED

IN SEGMENTS

\section{VESSEL}

DESCRIPTION

$\frac{\text { QUANTITY }}{2}$

$Q$ SAFETY ROD

8

$\bigoplus$ CORE SUBASSEMBLIES 105

INNER RADIAL BLANKET

SUBASSEMBLIES

32

$\square$ OUTER RADIAL BLANKET

SUBASSEMBLIES

499

W POSSIBLE STORAGE FOR CORE

OR INMER RADIAL BLANKET
SUBASSEMBLIES

THERMAL SHIELD IN

FORM OF STEEL RODS

THERMAL SHIELDING IN FORM

OF STEEL ROOS USED FOR

SURVEILLANCE TUBES

nEUTRON SOURCE LOCATION NO5NO4

SURVEILLANCE SUBASSEMBLY

location pol po3

TOTAL SUBASSEMBLIES

$\frac{1}{870}$

OSCILLATOR ROD TEMPORARY
LOCATION PO3POO

THE POSITION UNDER THE CENTER OF THE ROTATING PLUG, POONO9, IS VACANT

FIG. 2-REACTOR CROSS SECTION 
reactor vessel. The outer radial blanket and shielding lattice positions are both supplied with sodium coolant from a low-pressure plenum.

The reactor is controlled by two operating control rods and seven safety rods which are uniformly spaced around the center of the core. Provision for an eighth safety rod has been included in the design of the plant. The rods are all driven and actuated from the top. The rods are of the poison type, containing boron carbide $\left(\mathrm{B}_{4} \mathrm{C}\right)$ in which the boron is enriched in boron-10 (B-10). One operating control rod is used for regulating purposes and the other for shimming; the average reactivity insertion rates of these rods are approximately one cent per second and one cent per minute, respectively. Each control rod has a reactivity worth of approximately 46 cents ( $147 \mathrm{ih})$. The seven safety rods are worth more than $\$ 1.00$ ( $219 \mathrm{ih}$ ) each and provide shutdown reactivity. During operation of the reactor, they are held just above the upper axial blanket section of the core so that they can be rapidly inserted into the core if it becomes necessary to scram the reactor. During a normal shutdown, the safety rods are driven slowly into the core where they remain during refueling to provide the necessary shutdown reactivity.

A more detailed description of the Fermi reactor may be found in the Enrico Fermi Hazards Summary Report. 1

\section{B. TEMPERATURE EFFECTS IN THE REACTOR}

The Doppler coefficient is the only true, nuclear temperature coefficient in the reactor. All other components of the total isothermal temperature coefficient result from changes in either the reactor composition or reactor geometry due to thermal expansion of the core fuel, the core coolant, and the core steel structure, plus similar but lesser effects in the blanket. All of the components are predicted to be negative.

The Doppler coefficient is a small reactivity effect resulting from the broadening of the uranium fuel's cross-section resonances with increased temperature. This results in more neutron captures in the U-238, a negative reactivity effect, and more fissions in the U-235, a positive effect. Theory indicates that the two opposing reactivity effects are approximately equal in magnitude for a U-238 to U-235 atomic ratio of one. In the Fermi reactor core, the atomic ratio is about three and consequently the net Doppler effect is predicted to be negative.

The largest predicted temperature coefficient results from the radial core expansion which occurs as the reactor temperature increases. This expansion includes both the radial expansion of the steel subassembly wrapper cans at their point of contact near the core midplane, and the radial expansion of the upper and lower support structures of the core lattice. The 
reactivity effect of this expansion is negative because it causes fuel to be shifted radially outward in the core to a position of lesser worth.

The sodium temperature coefficient is another large contributor to the total isothermal temperature coefficient in the reactor. As the sodium coolant in the core is heated, it expands and the sodium density is decreased. In Fermi, the sodium coolant has a positive reactivity worth because the principal effect of the sodium is to reduce neutron leakage from the reactor; therefore, the reactivity effect due to a decrease in the sodium density when heated is of opposite sign, or negative.

The other major component of the temperature coefficient in the reactor is the reactivity effect resulting from expansion of the core fuel pins. The fuel pins expand both axially and radially inside their subassembly wrapper cans as the fuel temperature increases. The axial fuel pin expansion moves fuel axially outward to the core edge and the radial expansion of the fuel pins causes a displacement of sodium within the subassembly cans. Therefore, the temperature coefficients resulting from these two thermal expansions are analogous to those resulting from the core radial expansion and the core sodium expansion, respectively, and their values, although smaller, are negative also.

The other components of the total isothermal temperature coefficient are small effects due to similar thermal expansions of the blanket fuel, the blanket coolant and the blanket structure.

\section{PREDICTED VALUE OF THE ISOTHERMAL TEMPERATURE COEFFICIENT}

As described above, the components of the total isothermal temperature coefficient of reactivity in the Enrico Fermi reactor are the Doppler coefficient and the various coefficients due to thermal expansion of the reactor fuel, coolant, and structure. The total isothermal temperature coefficient is the sum of the various components. The predicted values for each of the components were based on calculations described in detail in Reference 1. Briefly, the method of calculation in each case was as follows:

Doppler Coefficient - The Doppler coefficient was calculated by a statistical method ${ }^{2}$ in which the reactivity effect of the broadening of the fuel's cross-section resonances with temperature was calculated using the assumption that the resonances are isolated and do not overlap. The effect of inelastic neutron scattering was also included. The integral effect over the entire core was obtained by the calculational method used.

Expansion Coefficients - The expansion temperature coefficients result from slight movements of the core materials, both fuel and 
structural, to locations of different reactivity worth as the temperature increases. This causes relatively small changes in the reactor composition and/or geometry, and the resulting reactivity effects were calculated by perturbation theory. In addition, because the reactor structure is elastic and the material properties (thermal expansion coefficients and moduli of elasticity) a re nearly independent of temperature, the reactivity effects due to expansion were calculated as the sum of the effects resulting from local temperature variations throughout the reactor. In practice, the local temperature coefficients for each component were found from structural deflection calculations and the local material danger coefficients of reactivity. The local temperature coefficients were then integrated over the entire core volume to obtain the isothermal temperature coefficient of each component.

Table I lists the calculated values of the various components of the isothermal temperature coefficient in the Fermi reactor at $550 \mathrm{~F} .1$ The predicted change in each component over the temperature range of $400 \mathrm{~F}$ to $600 \mathrm{~F}$ is also given in Table I. This latter information is shown because it corresponds to the experimental data obtained in the third part of the test (Section III, A. 3). With the exception of the Doppler coefficient, the predicted change over this temperature range is relatively small for all the components. The temperature dependence of the Doppler coefficient was calculated using the approximation that its value varies inversely as the three-halves power of the absolute temperature. The temperature dependence of each of the various expansion temperature coefficients was calculated from the material thermal expansion coefficient data shown in Figure 3. Based on the se data, the predicted increase in the absolute value of the total negative isothermal temperature coefficient between $400 \mathrm{~F}$ and $600 \mathrm{~F}$ is 6.0 per cent.

The predicted temperature dependence of the temperature coefficient may also be expressed in equation form. Using the data from Table I, and assuming that the coefficient varies linearly with temperature, $t$, over this range, the slope of the predicted straight line fit to the data is:

$$
\begin{aligned}
\text { Slope } & =\frac{\text { ITCR } t_{2}-I_{2} \text { CR }_{t_{1}}}{\mathrm{t}_{2}-\mathrm{t}_{1}} \\
& =\frac{[(-0.938)-(-0.885)] \mathrm{ih} / \mathrm{F}}{200 \mathrm{~F}} \\
& =-2.65 \times 10^{-4} \mathrm{ih} / \mathrm{F}^{2}
\end{aligned}
$$

The linear equation for the predicted isothermal temperature coefficient of reactivity as a function of temperature can then be written as:

$$
\operatorname{ITCR}=-0.912+\left(-2.65 \times 10^{-4}\right)(\mathrm{t}-500) \mathrm{ih} / \mathrm{F}
$$




\section{i}

TABLE I - PREDICTED ISOTHERMAL TEMPERATURE COEFFICIENT OF REACTIVITY

\begin{tabular}{|c|c|c|c|c|c|}
\hline \multirow[t]{2}{*}{ Component } & \multirow[t]{2}{*}{$\begin{array}{l}\text { Calculated Value } \\
\text { at } 550 \mathrm{~F}, \mathrm{ih} / \mathrm{F}^{\mathrm{a}} \\
\end{array}$} & \multicolumn{2}{|c|}{$\begin{array}{l}\text { Predicted Change Relative } \\
\text { to } 550 \mathrm{~F}, \text { Per Cent } \\
\end{array}$} & \multicolumn{2}{|c|}{$\begin{array}{c}\text { Predicted Values at } \\
\text { New Temperature, ih/F } \\
\end{array}$} \\
\hline & & $\underline{400 \mathrm{~F}}$ & $600 \mathrm{~F}$ & $400 \mathrm{~F}$ & $600 \mathrm{~F}$ \\
\hline Doppler & -0.069 & +27.5 & -7.0 & -0.088 & -0.064 \\
\hline Fuel Pin Expansion & -0.165 & -10.0 & +3.5 & -0.149 & -0.171 \\
\hline Sodium Expansion & -0.303 & -3.4 & +1.1 & -0.293 & -0.306 \\
\hline Core Radial Expansion & -0.380 & -8.6 & +2.2 & -0.347 & -0.388 \\
\hline Blanket Expansions & -0.009 & -8.6 & +2.2 & -0.008 & -0.009 \\
\hline Total Coefficient & -0.926 & $-4.5^{b}$ & $+1.5^{b}$ & -0.885 & -0.938 \\
\hline
\end{tabular}

a. The reactivity conversions for the Fermi reactor are:

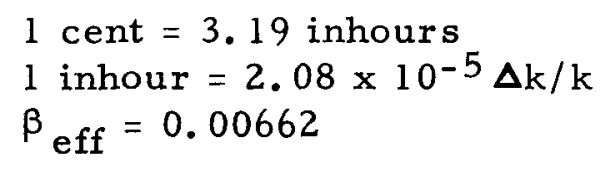

b. Weighted value for all components. 


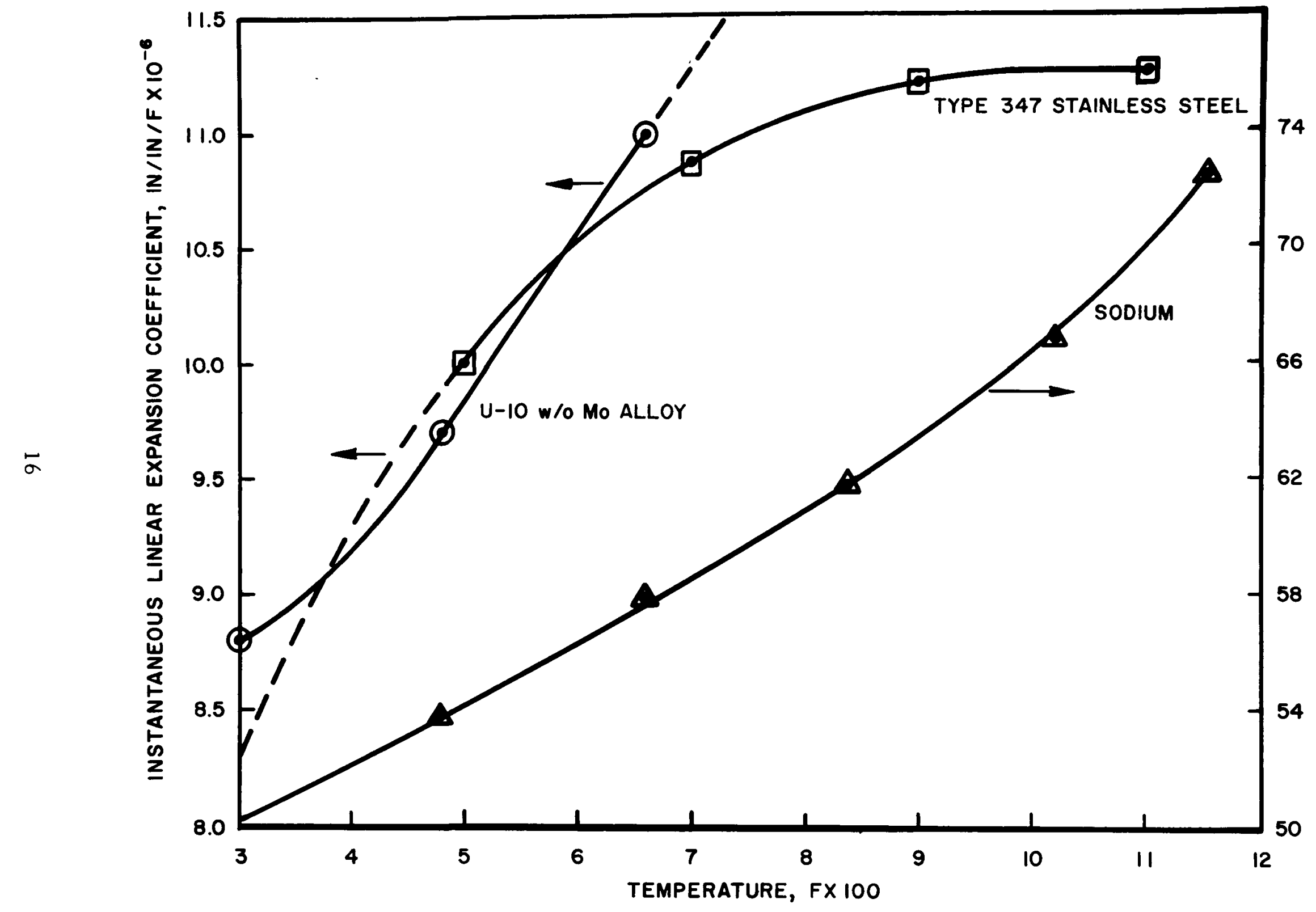

FIG. 3-VARIATION OF THERMAL EXPANSION COEFFICIENTS WITH TEMPERATURE 
In this equation, $t$ is the isothermal reactor temperature in degrees Fahrenheit. The equation is valid only for the temperature range of $400 \mathrm{~F}$ to $600 \mathrm{~F}$. The first term, $-0.912 \mathrm{ih} / \mathrm{F}$, is the predicted value of the coefficient at $500 \mathrm{~F}$ obtained by linear extrapolation of the data in Table $I$. The equation is given in this form, with the reference intercept axis translated to $500 \mathrm{~F}$, because the experimental data obtained in the third part of the test was fitted to an equation of this form (Section VI, B).

The previous discussion shows that the calculation of the isothermal temperature coefficient of reactivity for the Enrico Fermi reactor was complex and it required knowledge of many aspects of the reactor design. Calculation of the expansion temperature coefficients required detailed knowledge of the spatial reactivity worths and thermal expansion coefficients of the reactor fuel, coolant, and structural materials. It also required knowledge of the complex structural expansions which occur in the reactor with temperature. Calculation of the Doppler coefficient required detailed information on the neutron cross sections of the fuel in the resonance region. Because of the complexity of the calculations, and the fact that much of the basic data were not well known, the uncertainty assigned to the calculated isothermal temperature coefficient was large. Therefore, the close agreement between the predicted value and the experimental value which was subsequently determined by measurement, was an important confirmation of the validity of the calculational model used for temperature-reactivity feedback studies in the design of the Fermi reactor. 


\section{EXPERIMENTAL PROCEDURE}

\section{A. DESCRIPTION OF TEST}

The three measurements of the isothermal temperature coefficient of reactivity of the Enrico Fermi reactor were made in accordance with detailed, preplanned procedures. $3,4,5$ Prior to the conduct of the test, the procedures were reviewed for all aspects of completeness and safety. Revisions were made to incorporate improvements, and additional steps were added where necessary to facilitate the acquisition of complete and precise data during the tests. These procedures were also the basis used by the operating staff of the Enrico Fermi Power Plant in the preparation of operating guides for the conduct of the test.

\section{Measurements Over the Temperature Range $400 \mathrm{~F}$ to $520 \mathrm{~F}$}

A preliminary measurement of the isothermal temperature coefficient of reactivity was made on September 3 and 4, 1963, concurrent with absolute power calibration measurements. With the primary system temperature at $407.1 \mathrm{~F}$ isothermal, the reactor was made critical at a power level of 112 watts and the critical operating control rod positions were measured. The primary system temperature was then raised to $518.1 \mathrm{~F}$ isothermal, the reactor was once again made critical at a power level of 112 watts and the new critical rod positions were measured. The loss in reactor reactivity for this temperature increase, as evidenced by the different critical rod positions at the two temperatures, was then determined using the preliminary rod calibration data obtained during the initial loading to criticality of the reactor. ${ }^{6}$ From these data, the average isothermal temperature coefficient could be determined by dividing the measured reactivity change by the change in temperature.

\section{Measurements Over the Temperature Range $500 \mathrm{~F}$ to $540 \mathrm{~F}$}

The second set of measurements of the isothermal temperature coefficient of reactivity was made over the narrow range of temperature from $500 \mathrm{~F}$ to $540 \mathrm{~F}$. This included the system temperature, $517 \mathrm{~F}$, used in the majority of the low-power tests. The use of a retractable antimonyberyllium ( $\mathrm{Sb}-\mathrm{Be})$ neutron source located in the core position normally designated for the oscillator rod (Figure 2) eliminated the need for applying source neutron reactivity corrections to the measured data. The primary system was adjusted to the specified temperatures required in the test by using the primary system cold trap, and was held at these temperatures with minimum drift by making variations in the primary sodium flow rate (Section III, B). The instrumentation used to acquire the data is discussed in Section III, C of this report. 
The experimental procedure used in this portion of the test was straightforward. Starting at a reactor temperature of $540 \mathrm{~F}$, the critical control rod positions were determined and a reference positive period measurement was made. The reactor temperature was then lowered to $500 \mathrm{~F}$ in two $20 \mathrm{~F}$ increments and the reactivity change resulting from each temperature change was determined from the difference in the critical rod positions at each temperature. The reactivity effect of lowering the temperature was also determined from the difference in the positive periods measured at each temperature with the rods set at the $540 \mathrm{~F}$ reference period position, and also from the positive periods measured with the rods set at the critical positions found earlier at the higher temperatures. A detailed description of the experimental procedure is given below.

a. The primary sodium system temperature was adjusted to a nominal isothermal value of $540 \mathrm{~F}$ and held there with minimum drift $(-0.68$ $\mathrm{F} / \mathrm{hr}$ ) by maintaining the primary sodium flow rate at $7.19 \times 10^{6} \mathrm{lb} / \mathrm{hr}$. $^{*}$

The reactor was brought to criticality at a power level of $\sim 600$ watts on the shim and regulating control rods; the critical rod positions, the reactor power, the power drift rate, and the primary system temperatures were recorded.

The regulating rod was withdrawn to a position that put the reactor on a 189.7-second positive period. The rod position, reactor temperature, and period data were recorded. The regulating rod position used in this step was used as a reference for the comparative period measurements at lower temperatures in the test.

b. The reactor was shut down and the temperature of the primary sodium system was lowered $20 \mathrm{~F}$ to a nominal isothermal value of $520 \mathrm{~F}$. It was held at this value with minimum drift $(+0.36 \mathrm{~F} / \mathrm{hr})$ by maintaining the primary sodium flow rate at $6.78 \times 10^{6} \mathrm{lb} / \mathrm{hr}$.

With the shim rod set at the critical position determined at $540 \mathrm{~F}$, the reactor was brought to criticality at a power level of $\sim 600$ watts on the regulating rod. The critical rod position, the reactor power, the power drift rate, and the reactor temperature data were recorded.

The reactor power was reduced by inserting the regulating rod. The regulating rod was returned to the critical position established at $540 \mathrm{~F}$ and the resulting positive period was measured. The rod position, the reactor temperature, and the period data were recorded.

* All sodium flows given refer to 3-loop operation unless otherwise stated. 
The reactor was taken off the positive period and the power reduced by reinserting the regulating rod. The regulating rod was then returned to the position used for the reference period measurement at $540 \mathrm{~F}$ and the resulting positive period was measured and recorded. The rod positions and reactor temperatures were also measured and recorded.

c. The reactor was shut down and the primary sodium system temperature was reduced another $20 \mathrm{~F}$ to a nominal isothermal value of $500 \mathrm{~F}$. It was held at this value with minimum drift $(+0.04 \mathrm{~F} / \mathrm{hr})$ by maintaining the primary sodium flow rate at $6.61 \times 10^{6} \mathrm{lb} / \mathrm{hr}$. With the shim rod set at the critical position determined at $540 \mathrm{~F}$, the reactor was brought to criticality at a power level of $\sim 600$ watts on the regulating rod. The critical rod position, the reactor power, the power drift rate, and the reactor temperature data were recorded.

The reactor power was reduced by inserting the regulating rod. The regulating rod was returned to its critical position determined at $520 \mathrm{~F}$ and the resulting positive period was measured and recorded. The rod positions and reactor temperatures were also measured and recorded.

The reactor was taken off the positive period and the power reduced by reinserting the regulating rod. The regulating rod was returned to the critical position determined at $540 \mathrm{~F}$, and the resulting positive period was measured and recorded. The rod positions and reactor temperatures were also measured and recorded.

\section{d. The reactor was shut down.}

\section{Measurements Over the Temperature Range $400 \mathrm{~F}$ to $600 \mathrm{~F}$}

The third set of measurements of the isothermal temperature coefficient of reactivity was made over a range of temperatures from $400 \mathrm{~F}$ to $600 \mathrm{~F}$. The retractable $\mathrm{Sb}-\mathrm{Be}$ neutron source was also in place in the reactor during these measurements and it was possible to conduct the test at low power levels with no corrections being required for source neutron contributions to reactivity. As in the previous measurements, the primary system was adjusted to the required temperatures, using the cold trap, and was held at these temperatures with minimum drift by making variations in the primary sodium flow rate. The instrumentation used to acquire the data is discussed in Section III, C of this report.

The experimental procedure used in this portion of the test was similar to that used for the measurements over the temperature range $500 \mathrm{~F}$ to $540 \mathrm{~F}$. Starting at a reactor temperature of $600 \mathrm{~F}$, the critical positions of the operating control rods were determined. This was done with the shim rod fully withdrawn. The reactor temperature was then lowered to $400 \mathrm{~F}$, in $40 \mathrm{~F}$ increments, and the reactivity changes that resulted from the tem- 
perature changes were determined from the difference in the critical rod positions at each temperature. The reactivity effect of lowering the temperature was also determined from positive period measurements made with the rods set at the critical positions found previously at higher temperatures. Because of the relatively large reactivity increase which occurred in the reactor as the temperature was being lowered $200 \mathrm{~F}$, the critical position of the shim rod had to be changed during the course of the measurements. The shim rod was moved, half-way through the test, from its initial fully withdrawn critical position to a partially inserted position; near the end of the test, it was moved to a fully inserted position. A detailed description of the experimental procedure used is given below.

a. The primary sodium system temperature was raised to a nominal isothermal value of $600 \mathrm{~F}$. It was held at this value with minimum drift $(+0.03 \mathrm{~F} / \mathrm{hr})$ by maintaining the primary sodium flow rate at $8.42 \times 10^{6}$ $\mathrm{lb} / \mathrm{hr}$. Prior to making the temperature coefficient measurements, a series of mechanical measurements were made on the control rod extensions to determine the fully inserted positions of each of the two operating control rods at this temperature. The data from these measurements were compared to similar data obtained later at $400 \mathrm{~F}$ to determine the vertical growth of the control rod extensions with temperature.

b. The reactor was brought to criticality at a power level of $\sim 100$ watts on the regulating rod, with the shim rod fully withdrawn. The critical rod positions, reactor power, power drift rate, and primary system temperatures were recorded. To improve the statistical accuracy of the data, the reactor was made subcritical by inserting the regulating rod and the critical measurements were repeated.

c. The temperature of the primary system was reduced $40 \mathrm{~F}$ to a nominal isothermal value of $560 \mathrm{~F}$. It was held at this value with minimum drift $(+0.4 \mathrm{~F} / \mathrm{hr})$ by maintaining the primary sodium flow rate at $6.78 \mathrm{x}$ $10^{6} \mathrm{lb} / \mathrm{hr}$.

The reactor was brought to criticality at a power level of 100 watts on the regulating rod, with the shim rod fully withdrawn. The critical rod positions, reactor power, power drift rate, and primary system temperatures were recorded. This measurement was repeated three times.

The regulating rod was set at the critical position determined at $600 \mathrm{~F}$ and the resulting positive period was measured. The rod position, reactor temperature, and positive period data were recorded. This measurement was also repeated three times.

d. The reactor was shut down and the temperature of the primary sodium system was reduced another $40 \mathrm{~F}$ to a nominal isothermal 
value of $520 \mathrm{~F}$. It was held at this value with minimum drift $(+0.15 \mathrm{~F} / \mathrm{hr})$ by maintaining the primary sodium flow rate at $6.78 \times 10^{6} \mathrm{lb} / \mathrm{hr}$.

The reactor was brought to criticality at a power level of $\sim 100$ watts on the regulating rod, with the shim rod fully withdrawn. The rod positions, reactor power, power drift rate, and primary system temperatures were measured and recorded.

The regulating rod was returned to the critical position determined at $560 \mathrm{~F}$ and the resulting positive period was measured and recorded. The rod positions and reactor temperatures were also measured and recorded. This measurement was repeated once, and all data again recorded.

An additional critical regulating rod measurement was made at $520 \mathrm{~F}$ with the shim rod partially rather than fully withdrawn 16.00 inches withdrawn). The critical rod positions, reactor power, power drift rate, and temperatures were recorded. This measurement established new critical regulating and shim rod positions for the comparative critical rod and positive period reactivity measurements which were made at the next lower temperature. New reference positions were needed because of the relatively large increase in reactor reactivity that had occurred due to lowering the temperature $80 \mathrm{~F}$.

e. The reactor was shut down and the temperature of the primary system was reduced $40 \mathrm{~F}$ more to a nominal isothermal value of $480 \mathrm{~F}$. It was held at this value with minimum drift $(+0.20 \mathrm{~F} / \mathrm{hr})$ by maintaining the primary sodium flow rate at $6.28 \times 10^{6} \mathrm{lb} / \mathrm{hr}$.

The reactor was brought to criticality at a power level of $\sim 100$ watts on the regulating rod, with the shim rod withdrawn 6.00 inches. The rod positions, reactor power, power drift rate, and reactor temperatures were recorded. This measurement was repeated once.

The regulating rod was returned to the critical position found at $520 \mathrm{~F}$ and the resulting positive period was measured and recorded. The rod position and reactor temperature data were also measured and recorded. This measurement was repeated once.

Another critical regulating rod measurement was made at $480 \mathrm{~F}$ with the shim rod fully inserted rather than withdrawn 6.00 inches. The critical rod position, reactor power, power drift rate, and reactor temperature data were measured and recorded. This measurement provided a reference point for the critical and period measurements made after subsequent temperature reductions in the test. 
f. The reactor was shut down and the temperature of the primary system was reduced by $40 \mathrm{~F}$ to a nominal isothermal value of $440 \mathrm{~F}$. It was held at this value with minimum drift $(+1.20 \mathrm{~F} / \mathrm{hr})$ by maintaining the primary sodium flow rate at $6.09 \times 10^{6} \mathrm{lb} / \mathrm{hr}$.

The reactor was brought up to criticality at a power level of l00 watts on the regulating rod, with the shim rod fully inserted. The rod positions, reactor power, power drift rate, and reactor temperatures were recorded. This measurement was repeated once, and all data were recorded.

The regulating rod was returned to the reference critical position found at $480 \mathrm{~F}$ and the resulting positive period was measured and recorded. The rod position and temperature data were also measured and recorded. This measurement was repeated once.

g. The reactor was shut down and the temperature of the primary system was reduced by $40 \mathrm{~F}$ to a nominal isothermal value of $400 \mathrm{~F}$. It was held at this value with minimum drift $(+0.58 \mathrm{~F} / \mathrm{hr})$ by maintaining the primary sodium flow rate at $6.03 \times 10^{6} \mathrm{lb} / \mathrm{hr}$.

The reactor was brought to criticality at a power level of 100 watts on the regulating rod, with the shim rod fully inserted. The rod position, reactor power, power drift rate, and reactor temperature data were recorded. This measurement was repeated once.

The regulating rod was set at the critical position determined at $440 \mathrm{~F}$ and the resulting positive period was measured and recorded. The rod position and temperature data were also measured and recorded. This measurement was repeated once.

h. The reactor was shut down and the mechanical measurements which had been made on the control rod extensions at $600 \mathrm{~F}$ were repeated to obtain the change in length of the extensions for a $200 \mathrm{~F}$ change in reactor isothermal temperature.

\section{B. REACTOR FUEL LOADINGS AND PLANT CONDITIONS}

The core fuel subassembly loadings used for each of the three sets of temperature coefficient measurements are given in Figures 4, 5, and 6. It will be noted that one less core subassembly was required for the last two measurements than for the first measurement. This is because the retractable $\mathrm{Sb}-\mathrm{Be}$ neutron source was in place in the reactor during these measurements. The $3.4 \mathrm{~kg}$ of beryllium which is contained in the retractable source, located as shown in Figures 5 and 6 , has a reactivity worth approximately equal to that of a core subassembly located at the edge of the core. The only limitation on the core loading during the test was that there must be less than 293.48 ih (92 cents) excess reactivity at any test temperature. Because the 


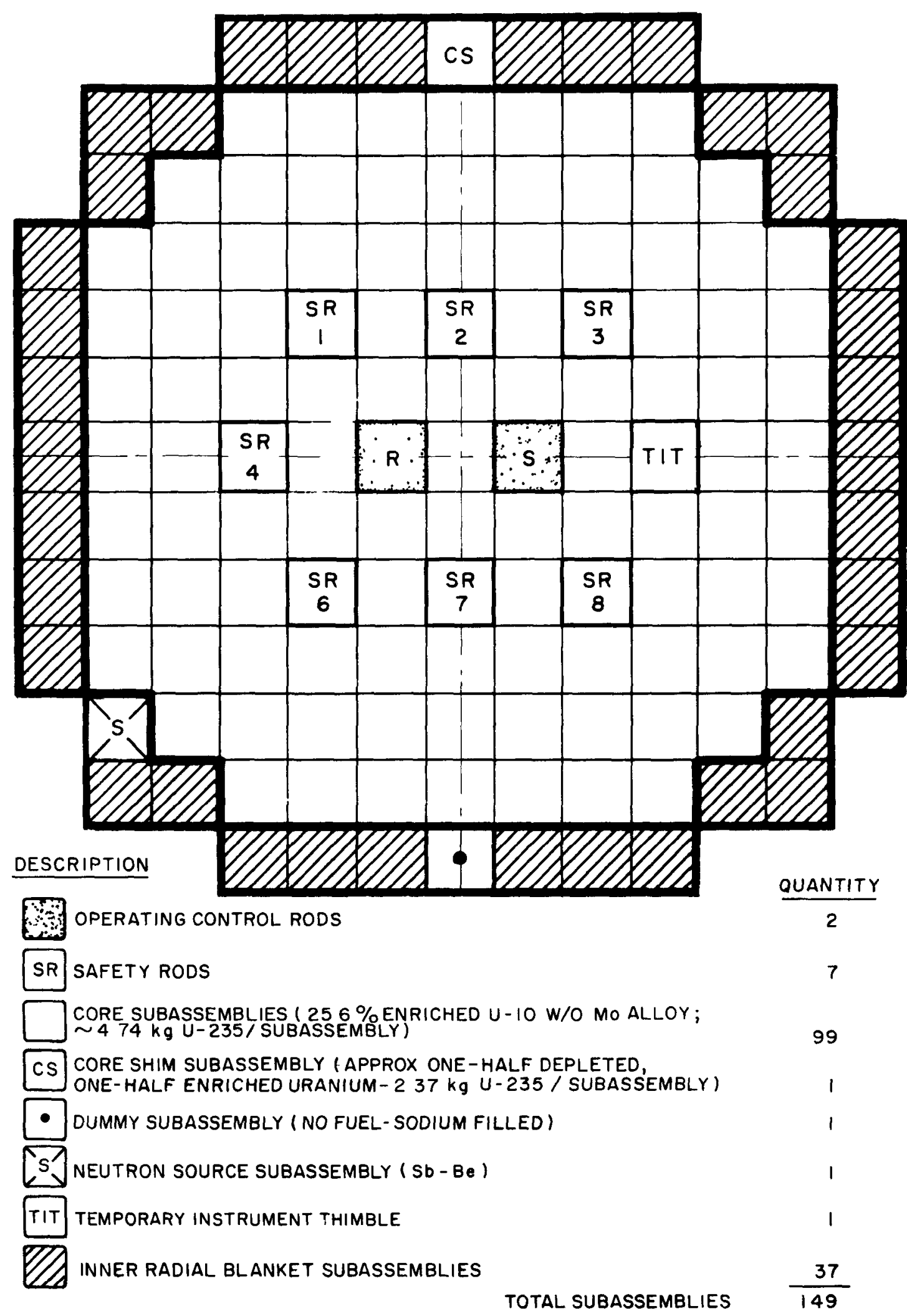

FIG.4-CORE LOADING FOR FIRST MEASUREMENT 4O0F TO $520 \mathrm{~F}$ 


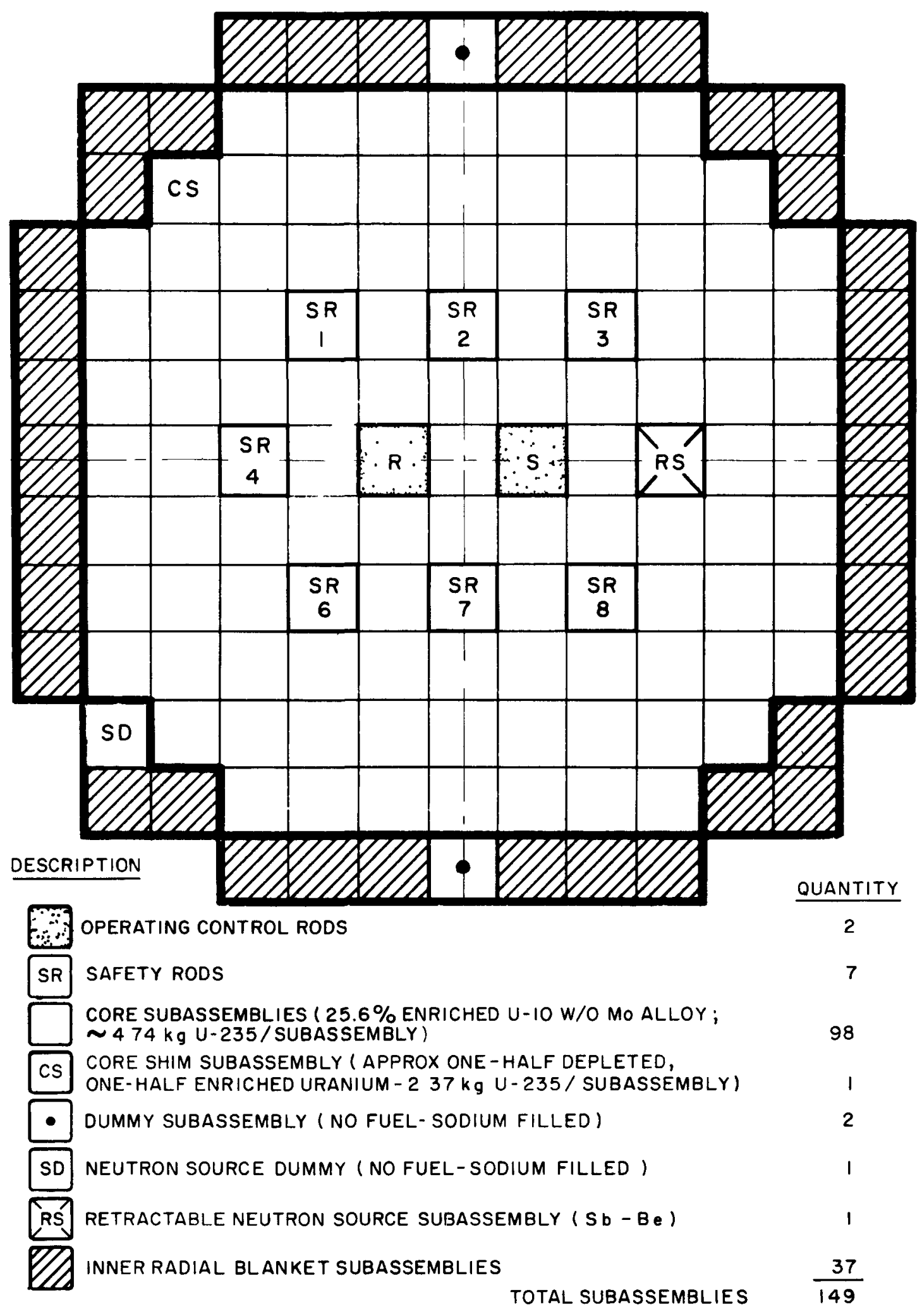

FIG.5-CORE LOADING FOR SECOND MEASUREMENT $500 \mathrm{~F}$ TO $540 \mathrm{~F}$ 


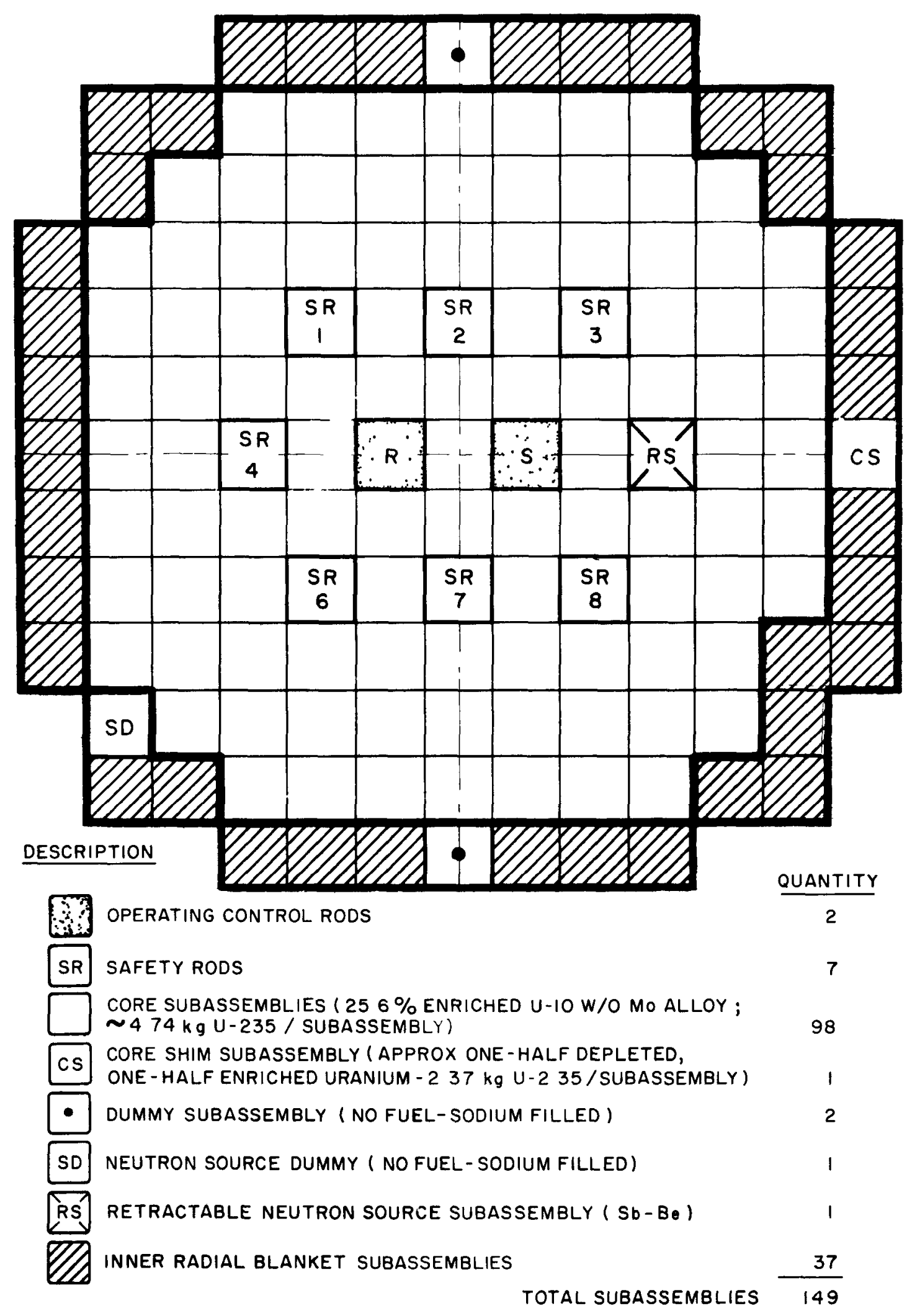

FIG. 6 - CORE LOADING FOR THIRD MEASUREMENT $400 \mathrm{~F}$ TO $600 \mathrm{~F}$ 
early determination of the value of the isothermal temperature coefficient was $-0.83 \mathrm{ih} / \mathrm{F}$, and the proposed range of test temperatures was a maximum of $200 \mathrm{~F}$, the maximum reactivity change anticipated was only about $166 \mathrm{ih}$; therefore, there was adequate latitude available for the core loadings. The maximum excess reactivity of the core loading used for the first set of measurements was $230 \mathrm{ih}$. This was the value at $400 \mathrm{~F}$, the lower temperature limit of the test. The maximum excess reactivities of each of the core loadings used for the second and third sets of measurements were the same, approximately $225 \mathrm{ih}$, this being the value at $400 \mathrm{~F}$ also.

The temperature of the primary system was increased to the required values in the first set of measurements by operating the primary sodium pumps at high flow rates and using their heat input, and by using the resistance and inductance heating available for the primary system. The maximum rate at which the temperature could be increased by this procedure was approximately $+6 \mathrm{~F} / \mathrm{hr}$. In the latter two sets of measurements, where the primary system temperature was reduced from one measurement to the next, the primary sodium pumps were put on minimum flow operation and the cold trap of the primary sodium service system was used to reduce the system temperature. The maximum rate of temperature decrease achieved using this method was approximately $-4 \mathrm{~F} / \mathrm{hr}$. Neither the secondary sodium system nor the steam-feedwater system was in service during the course of the measurements. When the desired temperature for a measurement was reached, it was maintained at this value with minimum drift by making minor adjustments in the primary sodium flow rate. The results of a previous test had demonstrated that variations in primary sodium coolant flow rate had no effect on reactivity at zero power. 7 Therefore, it was not necessary to correct the reactivity data for differences in sodium flow rates.

\section{INSTRUMENTATION}

The three parameters of primary interest in the test were the neutron signals during the time of the period and critical measurements, the primary system temperatures, and the operating control rod positions; however, data on sodium flows, cover gas pressure, reactor sodium level, and graphite shield temperatures were also taken.

\section{Nuclear Instrumentation}

Two high-sensitivity $\mathrm{BF}_{3}$ proportional detectors were used to determine reactor periods in the test. They were connected to the safety system source range instrumentation and to two RIDL scalers, switched with an Eagle Timer to count for 12 seconds every 15 seconds, located in the main control room. The count rate data obtained from the scalers were plotted on semi-logarithmic graph paper to obtain the reactor periods. Period information was also obtained from an ion chamber connected to a Keithley micromicroammeter located in the reactor control room. The output of 
the micromicroammeter was connected to a recorder that had back-set switches at 30 per cent and 81.5 per cent of full scale (an e-fold power increase); the switches operated a timer that gave a direct readout of the reactor period. The three periods thusly obtained were averaged for use in the analysis. The micromicroammeter was also used to determine the neutron flux (power) drift during critical rod position reactivity measurements. From these data, reactivity corrections for power drift could be made. The data from the normal source range and intermediate range detectors in the plant were also recorded to provide a reference in the event a failure occurred in the test instrumentation. All of the neutron detectors were located outside of the core inside detector guide tubes which penetrate the graphite shield surrounding the reactor vessel (Figure 7).

\section{Temperature Sensing Instrumentation}

Whenever temperature data were required in the test, eleven individual measurements of the temperature of the primary system were made using five thermocouples and six resistance temperature detectors which are part of the normal plant instrumentation. Each of the five thermocouples is connected through a switch to a common potentiometer. Four of the the rmocouples are mounted in the fingers of the hold-down mechanism and monitor the sodium temperatures at the outlet of three core subassemblies and one inner radial blanket subassembly. The fifth the rmocouple is located on the lower support plate and monitors the sodium temperature at the core inlet (Figure 1). Each of the six resistance temperature detectors is connected through a switch to a common resistance bridge. The six resistance detectors are located in the piping of the primary sodium system; one in each of the three 30-inch exit sodium pipes that leave the reactor and one in each of the three 6-inch inlet pipes that supply the low-pressure inlet plenum to the reactor (Figure 1).

The temperature data from the five thermocouples were used to determine the temperature drift rate in the test and the data from the six resistance temperature detectors were averaged to determine the isothermal temperature of the primary sodium system.

The temperature measuring systems, consisting of the sensing and measuring devices, were correlated in a preoperational test and correction factors were determined for each of the eleven temperature measuring channels. ${ }^{8}$ Curves were developed that permitted direct conversion of the test instrument readings to corrected temperatures.

\section{Rod Position Instrumentation}

During the test, the positions of the two operating control rods were determined from Gilmore digital indicators that were connected to position potentiometers located on the rod drives and from direct reading 


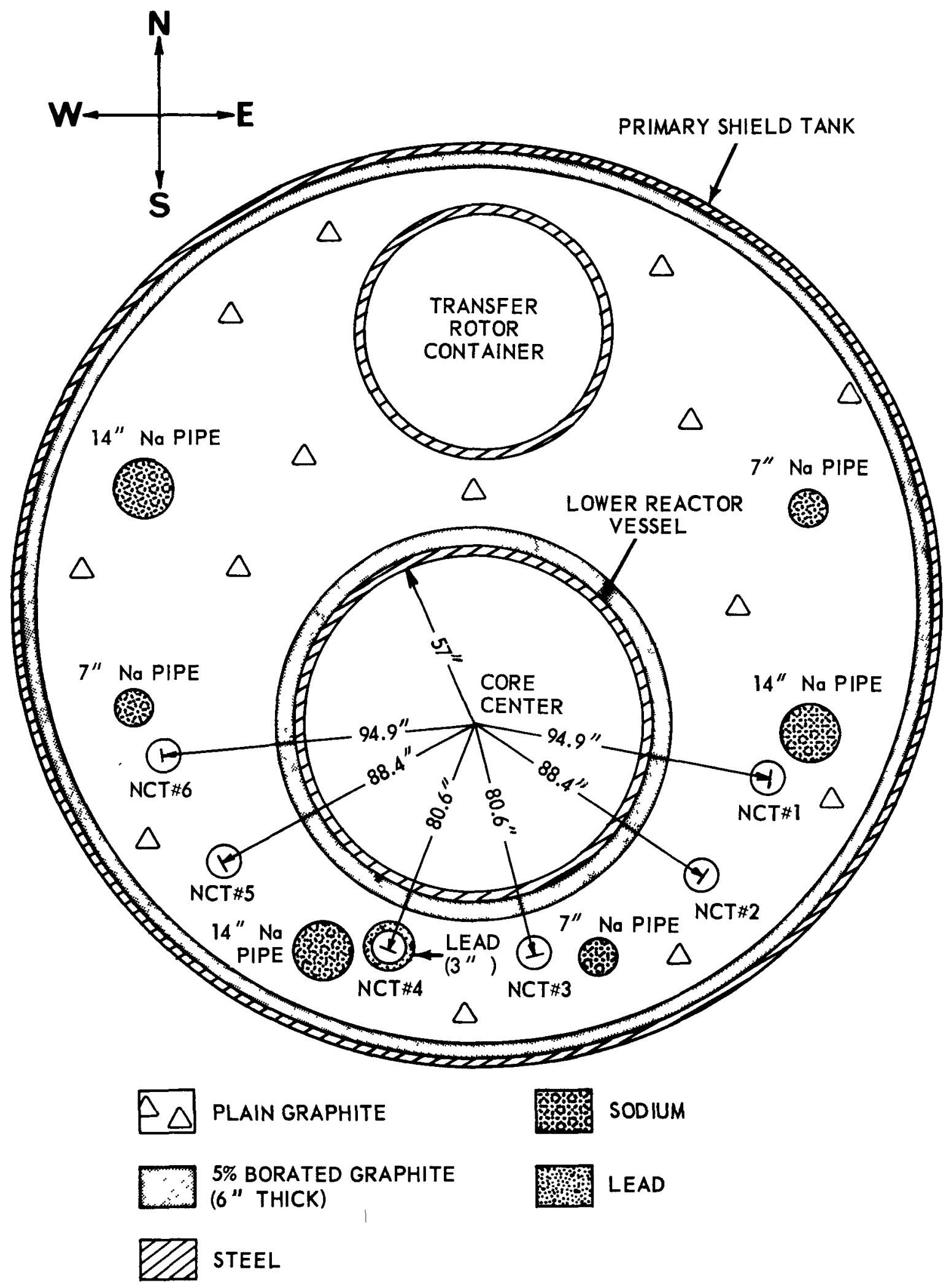

FIG. 7+LOCATION OF NEUTRON-COUNTER TUBES IN GRAPHITE SHIELD 
scales that were located at the rod drives. The data from the direct reading scales were the more accurate and were used almost exclusively in the analysis of the test.

\section{Miscellaneous Plant Instrumentation}

The normal plant instrumentation, described in Reference 1, was used to determine primary sodium flows, graphite shield temperatures, gas pressures, and sodium levels. The retractable Sb-Be neutron source used is described in Reference 9. 


\section{EXPERIMENTAL DATA}

The critical rod data obtained in the first measurement of the isothermal temperature coefficient of reactivity, over the temperature range $407 \mathrm{~F}$ to $518 \mathrm{~F}$, are summarized in Table II below.

\section{TABLE II - CRITICAL ROD DATA FROM THE FIRST MEASUREMENT}

\begin{tabular}{|c|c|c|c|}
\hline $\begin{array}{c}\text { Temperature } \\
\text { Range, } F \\
\end{array}$ & $\begin{array}{l}\text { Average Iso- } \\
\text { thermal Reactor } \\
\text { Temperature, } F\end{array}$ & $\begin{array}{c}\text { Critical Regulating } \\
\text { Rod Position, } \\
\text { Inches Withdrawn } \\
\end{array}$ & $\begin{array}{c}\text { Critical Shim } \\
\text { Rod Position, } \\
\text { Inches Withdrawn } \\
\end{array}$ \\
\hline $\begin{array}{l}407 \\
\text { to }\end{array}$ & 407.1 & 7.53 & fully inserted \\
\hline 518 & 518.1 & 13.34 & 5.02 \\
\hline
\end{tabular}

The experimental data from the second and third sets of measurements, over the temperature ranges $500 \mathrm{~F}$ to $540 \mathrm{~F}$ and $400 \mathrm{~F}$ to $600 \mathrm{~F}$, are summarized in Tables III and IV. Table III lists the critical rod data obtained in each of these two measurements, and Table IV lists the period data. The temperatures listed are the average of the temperatures measured by the six resistance temperature detectors. The rod position and power drift data listed were used to make minor reactivity corrections to account for small variations in reference rod positions and to account for small deviations from true criticality. The reactor periods measured by each of the three neutron detectors are individually tabulated and the average periods are also given. 
TABLE III - CRITICAL ROD DATA FROM THE SECOND AND THIRD MEASUREMENTS

\begin{tabular}{ccc}
$\begin{array}{c}\text { Temperature } \\
\text { Range, } F\end{array}$ & Run No. \\
\cline { 1 - 1 } 540 & & $65-4$ \\
to & & $67-4$ \\
500 & & $68-4$ \\
& & \\
& & $101-4$ \\
& & $101-5$ \\
& & $101-6$ \\
& & $101-8$ \\
& & $101-10$ \\
& & $101-12$ \\
& & $102-4$ \\
& & $103-4$ \\
& & $103-6$ \\
& & $103-8$ \\
& & $105-4$ \\
& & $106-4$
\end{tabular}

$\begin{array}{ccc}\begin{array}{c}\text { Average Iso- } \\ \text { thermal Reactor }\end{array} & \begin{array}{c}\text { Critical Regulating } \\ \text { Rod Position, } \\ \text { Temperature, F }\end{array} & \begin{array}{c}\text { Critical Shim } \\ \text { Rod Position, } \\ \text { Inches Withdrawn }\end{array}\end{array}$

539.48

519.92

500.17

599.52

599.56

561.24

561.34

560.72

560.17

520.15

519.98

480.01

480.33

480.58

440.90

441.18

400.17

400.02
8. 16

6.64

5.07

9.52

9.53

6.31

6.33

6.27

6.22

2. 99

12.50

8.40

8.42

18.79

11.35

11.38

7.55

7.55
Power Drift

Rate, Per Cent Per 5 Minutes

$$
\begin{aligned}
& 10.98 \\
& 10.97 \\
& 11.00
\end{aligned}
$$

19.90

19.90

19.90

19.90

19.90

19.90

19.99

5.96

5.96

5.97

fully inserted

fully inserted

fully inserted

fully inserted

fully inserted

0
0
0
-1.00
0
0
0
0
0
0
0
0
-0.67
0
0
0
-0.30
+0.33


TABLE IV - POSITIVE PERIOD DATA FROM THE SECOND AND THIRD MEASUREMENTS

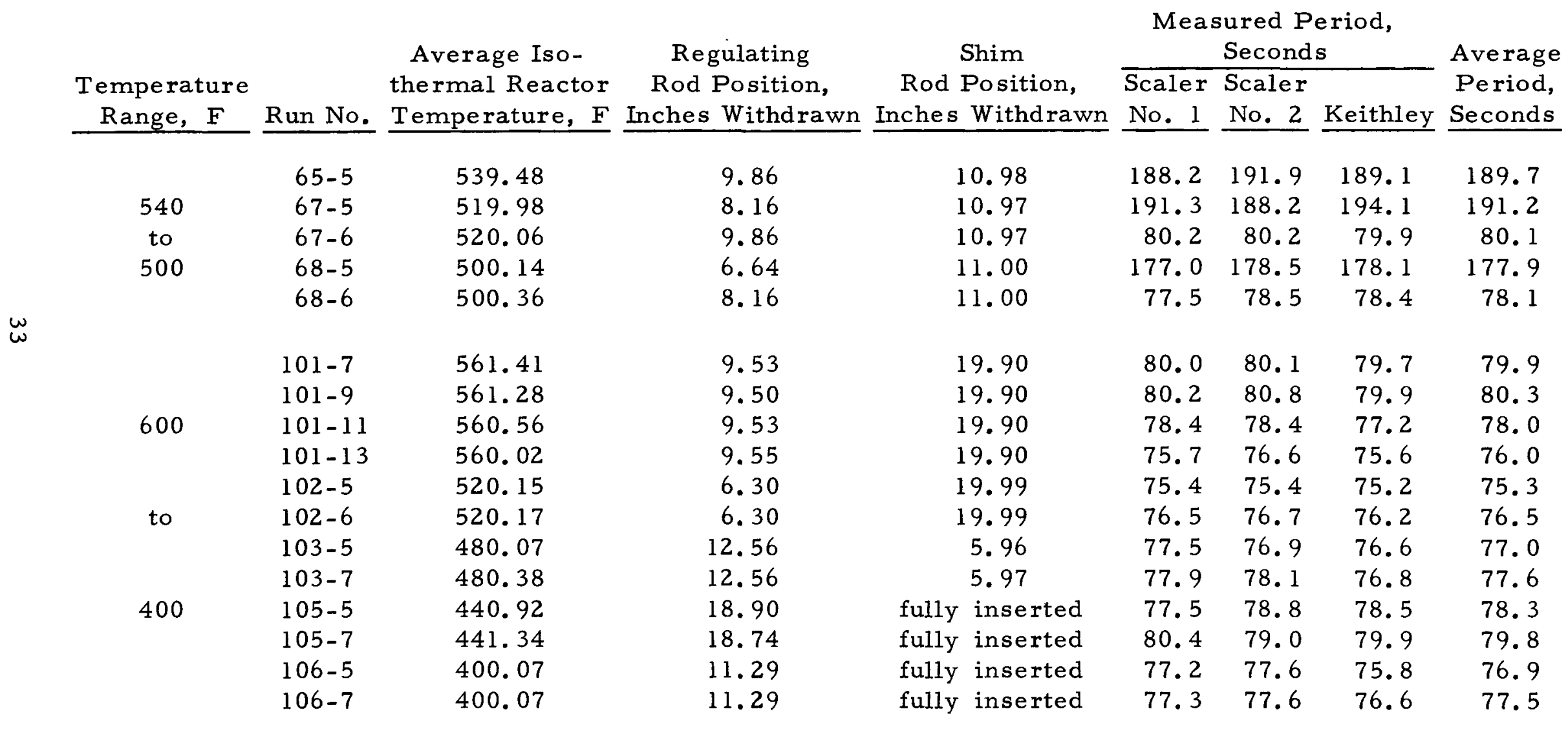




\section{MATHEMATICAL ANALYSIS OF THE DATA AND EXPERIMENTAL RESULTS}

\section{A. DETERMINATION OF THE ISOTHERMAL TEMPERATURE COEFFICIENT}

The isothermal temperature coefficient of reactivity was calculated using the critical rod and/or positive period data obtained in the measurements over the three different temperature ranges. The data were corrected for power drift and rod position errors where applicable.

\section{First Set of Measurements}

The analysis of the data obtained in the preliminary measurement of the isothermal temperature coefficient of reactivity (400 F to $520 \mathrm{~F}$ ) was a simple calculation of the ratio of the change in the excess reactivity of the reactor, pex, to the corresponding change in temperature, $t$

$$
\text { ITCR }=\frac{\rho \mathrm{ex}_{2}-\rho \mathrm{ex}_{1}}{\mathrm{t}_{2}-\mathrm{t}_{1}} \mathrm{ih} / \mathrm{F}
$$

where the subscripts 1 and 2 represent the two temperatures. Only critical rod data, shown in Table II, Section IV, were obtained in this portion of the test. The excess reactivities at each temperature were calculated from the critical rod data using the control rod calibration curves reported in Reference $6 . *$ The resulting values were:

$$
\begin{aligned}
\operatorname{\rho ex}_{1} & =219.6 \mathrm{ih} \\
\operatorname{pex}_{2} & =127.5 \mathrm{ih} \\
t_{1} & =407.1 \mathrm{~F} \\
t_{2} & =518.1 \mathrm{~F}
\end{aligned}
$$

therefore:

$$
\operatorname{ITCR}=\frac{127.5-219.6}{518.1-407.1}=-0.83 \mathrm{ih} / \mathrm{F}
$$

* These were preliminary rod calibration curves obtained early in the nuclear test program and the only ones available at the time the measurements were made. 


\section{Second and Third Sets of Measurements}

The second and third measurements of the isothermal temperature coefficient of reactivity $(500 \mathrm{~F}$ to $540 \mathrm{~F}$ and $400 \mathrm{~F}$ to $600 \mathrm{~F}$ ) were more detailed than the first and included both critical rod position data and positive period data.

a. Analysis of the Critical Rod Data - In making the critical rod measurements in the second and third parts of the test, the critical shim rod position at each temperature was very close to the critical shim rod position used at the preceding higher temperature. Therefore, the gross change in excess reactivity for the two different isothermal reactor temperature conditions, $\operatorname{ex}_{2}-\operatorname{\rho ex}_{1}$, could be determined from the difference in the critical regulating rod positions at each temperature. To obtain the reactivities, the regulating rod calibration curve shown in Figure 8 was used. The gross excess reactivity change was then corrected for any slight differences in the shim rod positions that might have existed and for any power drift that might have occurred if the reactor was not exactly critical at the time of either measurement. Thus, the equation used to determine the net excess reactivity change with temperature was:

$$
\Delta \rho e x=\rho e x_{2}-\rho x_{1}+\Delta \rho s+\Delta \rho d
$$

where:

$$
\begin{aligned}
\Delta p= & \text { net excess reactivity change, ih } \\
\operatorname{pex}_{1}= & \text { excess reactivity read from the regulating rod } \\
& \text { calibration curve for the critical position of } \\
& \text { the rod at higher temperature, } t_{1} \text {, ih } \\
\operatorname{pex}_{2}= & \text { excess reactivity read from regulating rod } \\
& \text { calibration curve for the critical position of } \\
& \text { the regulating rod at the lower temperature, } \\
& t_{2} \text {, ih } \\
\Delta \rho s= & \text { reactivity correction for differences in the } \\
& \text { reference shim rod position at the two tem- } \\
& \text { peratures, ih }
\end{aligned}
$$

This was obtained by multiplying the slope of the shim rod calibration curve (Figure 9) in its operating region by the difference in rod position. The sign of this term was plus or minus depending on whether the shim rod insertion at the lower temperature, $t_{2}$, was more or less than at the higher temperature, $t_{1}$, respectively. 


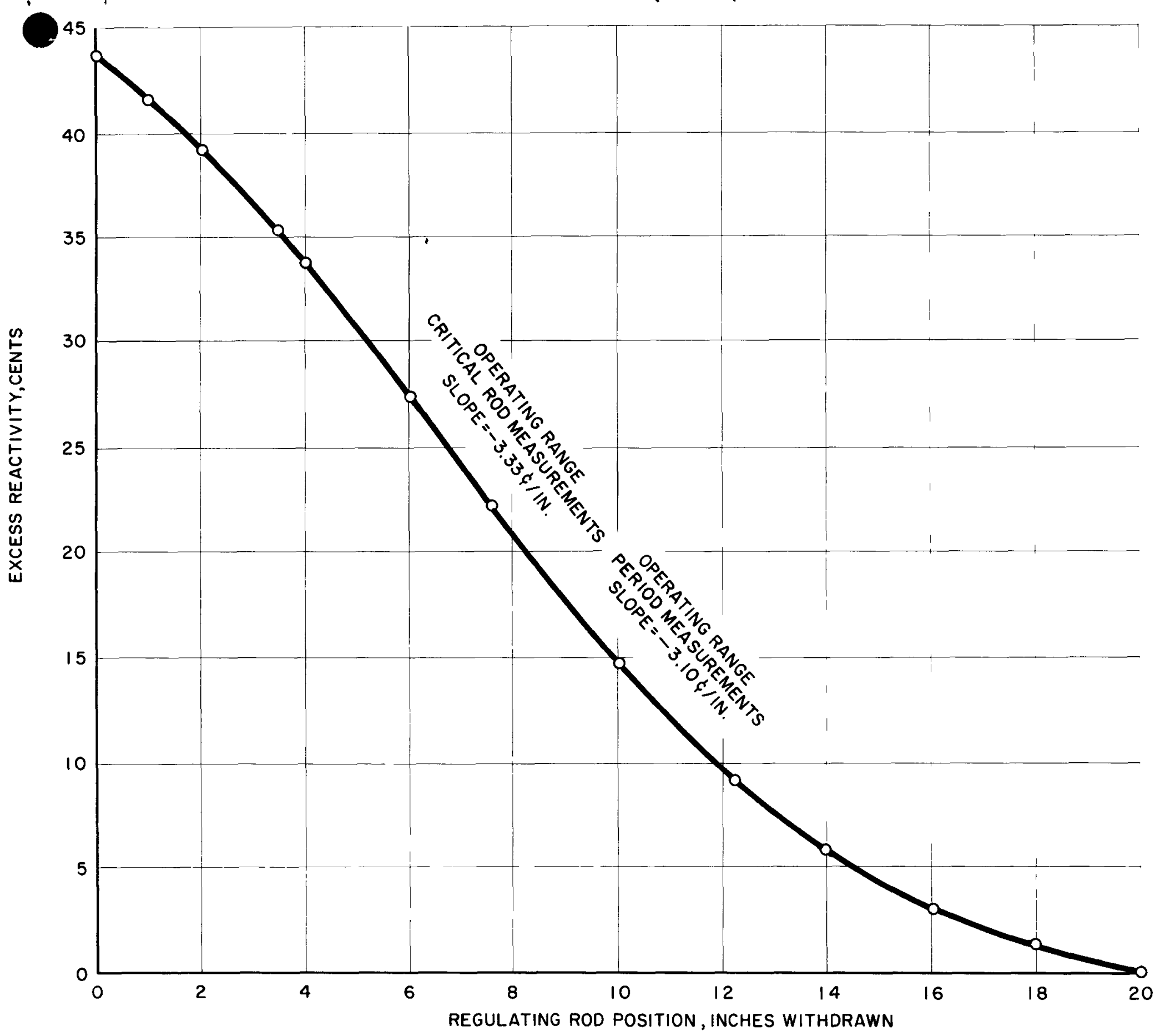

FIG. 8 - EXCESS REACTIVITY VERSUS CRITICAL REGULATING ROD POSITION 


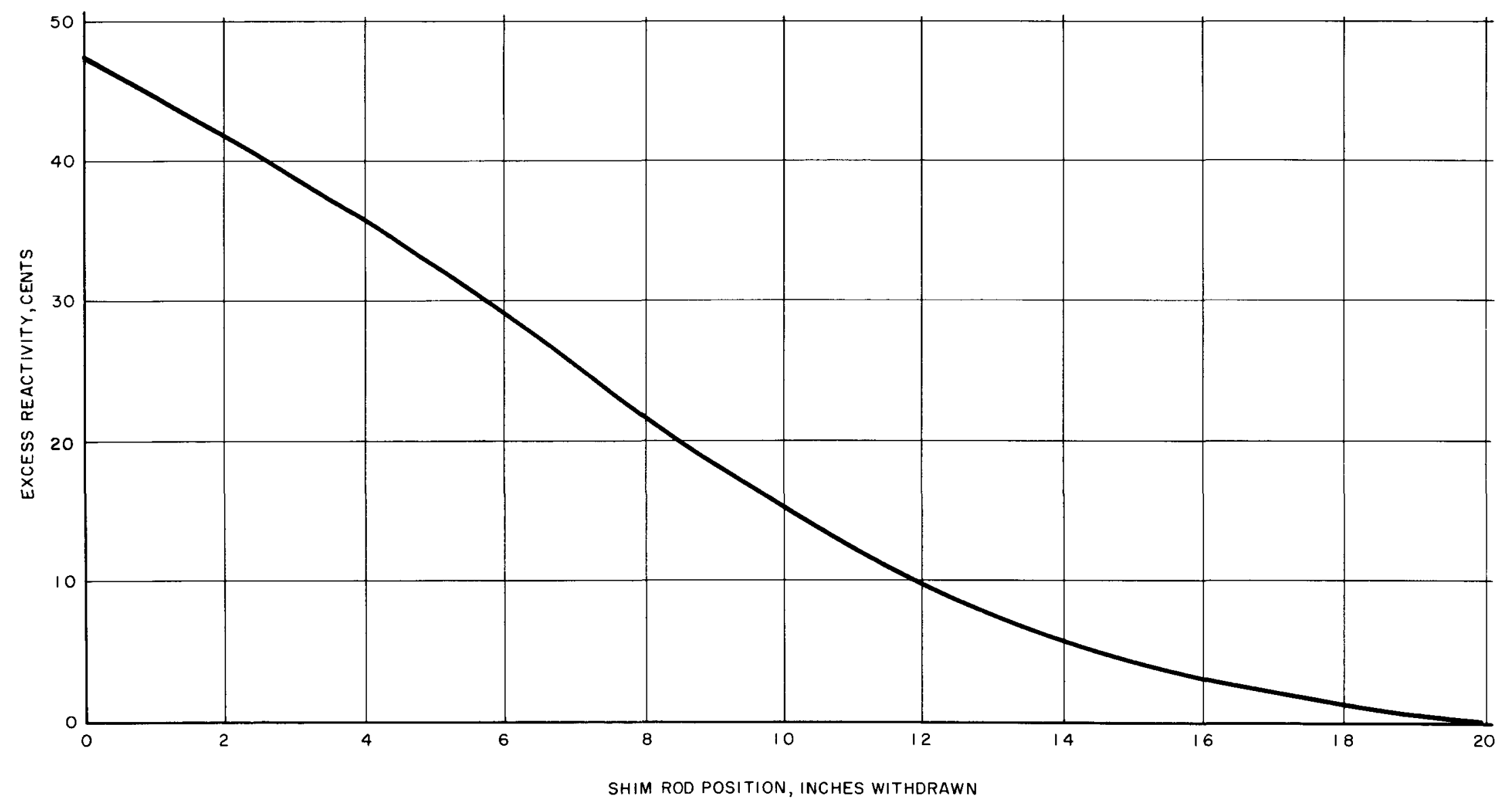

FIG. 9 - EXCESS REACTIVITY VERSUS CRITICAL SHIM ROD POSITION 


$$
\begin{aligned}
\Delta \rho d= & \text { reactivity correction for power drift which } \\
& \text { occurred during either of the two critical } \\
& \text { measurements, ih }
\end{aligned}
$$

This correction was equal to 0.12 ih per cent drift in five minutes. The sign of the correction at each temperature depended on the direction of the drift. If the drift was positive (upward) at $t_{1}$, the correction was negative and vice-versa. Conversely, at $t_{2}$ positive drift was a positive correction and vice-versa.

The equation used to find the value of the isothermal temperature coefficient in the temperature range $t_{1}$ to $t_{2}$ was:

$$
\operatorname{ITCR}=\frac{\Delta p e x}{t_{2}-t_{1}} \quad \text { ih } / F
$$

Table $\mathrm{V}$ lists the isothermal temperature coefficient values that were calculated from the data obtained in the second and third sets of measurements. The values in Table $\mathrm{V}$ are based on the critical rod data given in Table III, Section IV.

b. Analysis of the Positive Period Data - The one-period method was the principal experimental technique used in making period reactivity measurements in the second and third parts of the test. In this method, the reactivity effect of successively lowering the temperature was determined from the positive periods measured with the control rods set at the critical positions found at the preceding higher temperature. Thus, the gross excess reactivity change in the reactor for the two isothermal temperature conditions could be calculated directly from the inhour formula:

$$
\frac{\frac{\ell}{\tau k_{\text {eff }}}+\sum_{i=1}^{6} \frac{\beta_{i}}{1+\lambda_{i}{ }^{2}}}{\frac{\ell}{3600 k_{\text {eff }}}+\sum_{i=1}^{6} \frac{\beta_{i}}{1+3600 \lambda_{i}}}
$$

where:

$$
\begin{aligned}
\Delta \rho g= & \text { gross excess reactivity change between tempera- } \\
& \text { tures } t_{1} \text { and } t_{2}, \text { ih } \\
T= & \text { average period measured at the lower tempera- } \\
& \text { ture, } t_{2}, \text { with the rods set at the critical posi- } \\
& \text { tions found at the higher temperature, } t_{1} \text {, seconds }
\end{aligned}
$$


TABLE V - ISOTHERMAL TEMPERATURE COEFFICIENTS FROM CRITICAL ROD POSITION DATA

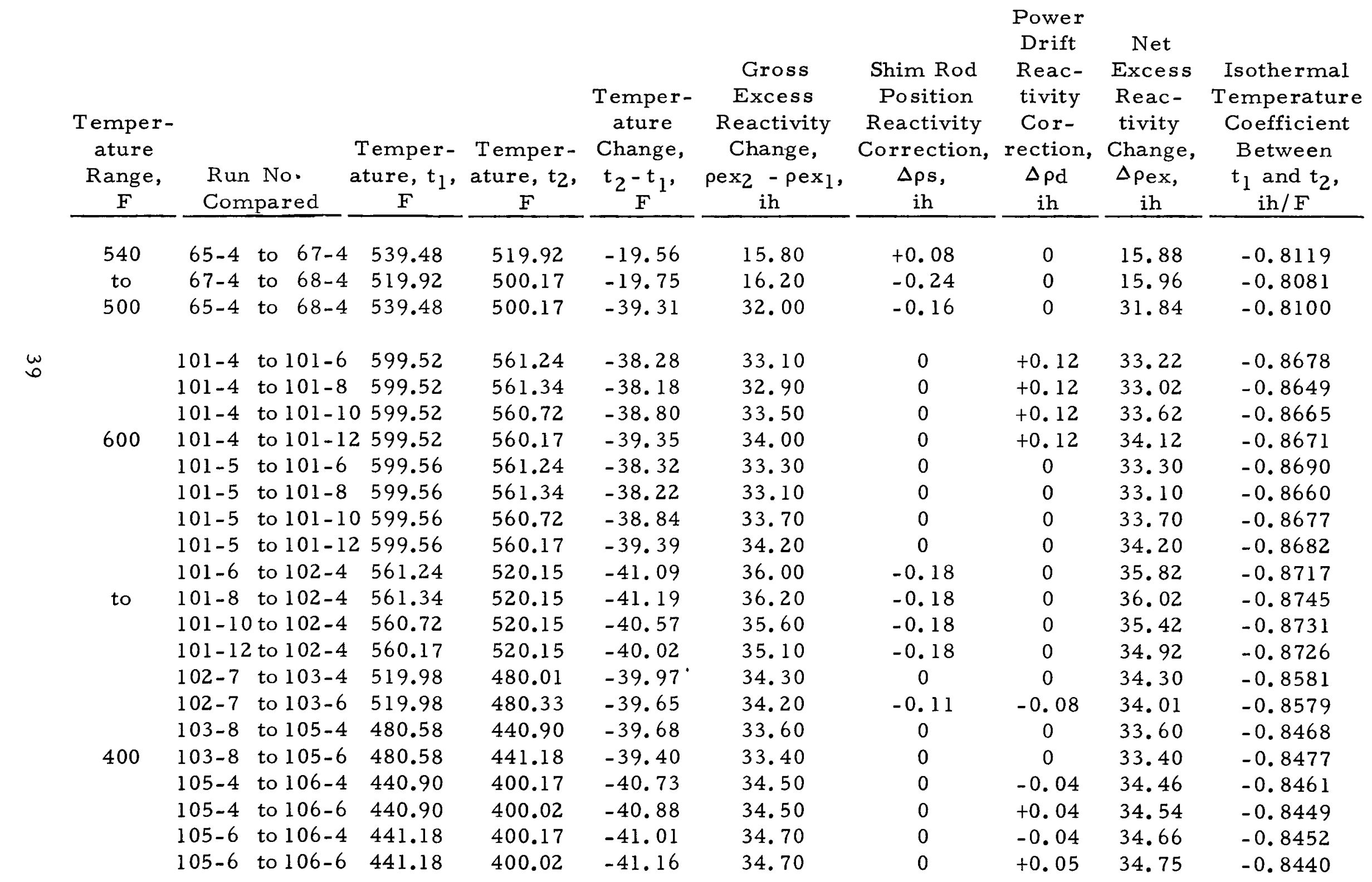




$$
\begin{aligned}
k_{\text {eff }}= & \text { effective multiplication factor } \sim 1.00^{*} \\
\ell= & \text { prompt neutron lifetime, seconds } \\
i= & \text { delayed neutron group }(i=1 \text { to } 6) \\
\beta_{i}= & \text { effective delayed neutron fraction for the } i^{\text {th }} \\
& \text { group of delayed neutrons } \\
i= & \text { precursor decay constant for the } i^{\text {th }} \text { group } \\
& \text { of delayed neutrons, sec }-1
\end{aligned}
$$

The values of $\ell, \beta_{i}$, and $\lambda_{i}$ for the Fermi reactor which were used in the calculations are given in Table VI. The relationship between the period, $T$, and the excess reactivity for the Fermi reactor calculated from Equation (7) is shown graphically in Figure 10.

\section{TABLE VI - DELAYED AND PROMPT NEUTRON DATA FOR THE FERMI REACTOR}

Group, i

1

2

3

4

5

6
Effective Delay

Fraction, $\beta_{i}$
Precursor Decay

Constant, $\lambda_{i}, \sec ^{-1}$

0.01275

0.03196

0.12040

0.32260

1. 40500

3.94400

Prompt neutron lifetime: $\ell=1.38 \times 10^{-7} \mathrm{sec}$.

The gross reactivity change calculated from the period data was corrected for any small differences which existed in either the regulating or shim rod positions at the two temperatures and for any power drift which was measured during the critical rod determination at the higher temperature. Thus, the net excess reactivity change with temperature was:

$$
\Delta \rho e x=\Delta \rho g+\Delta \rho r+\Delta \rho d
$$

* A value of 1.00 could be used for $k_{\text {eff }}$ because of the relatively long periods (small excess reactivities) measured in the test. 


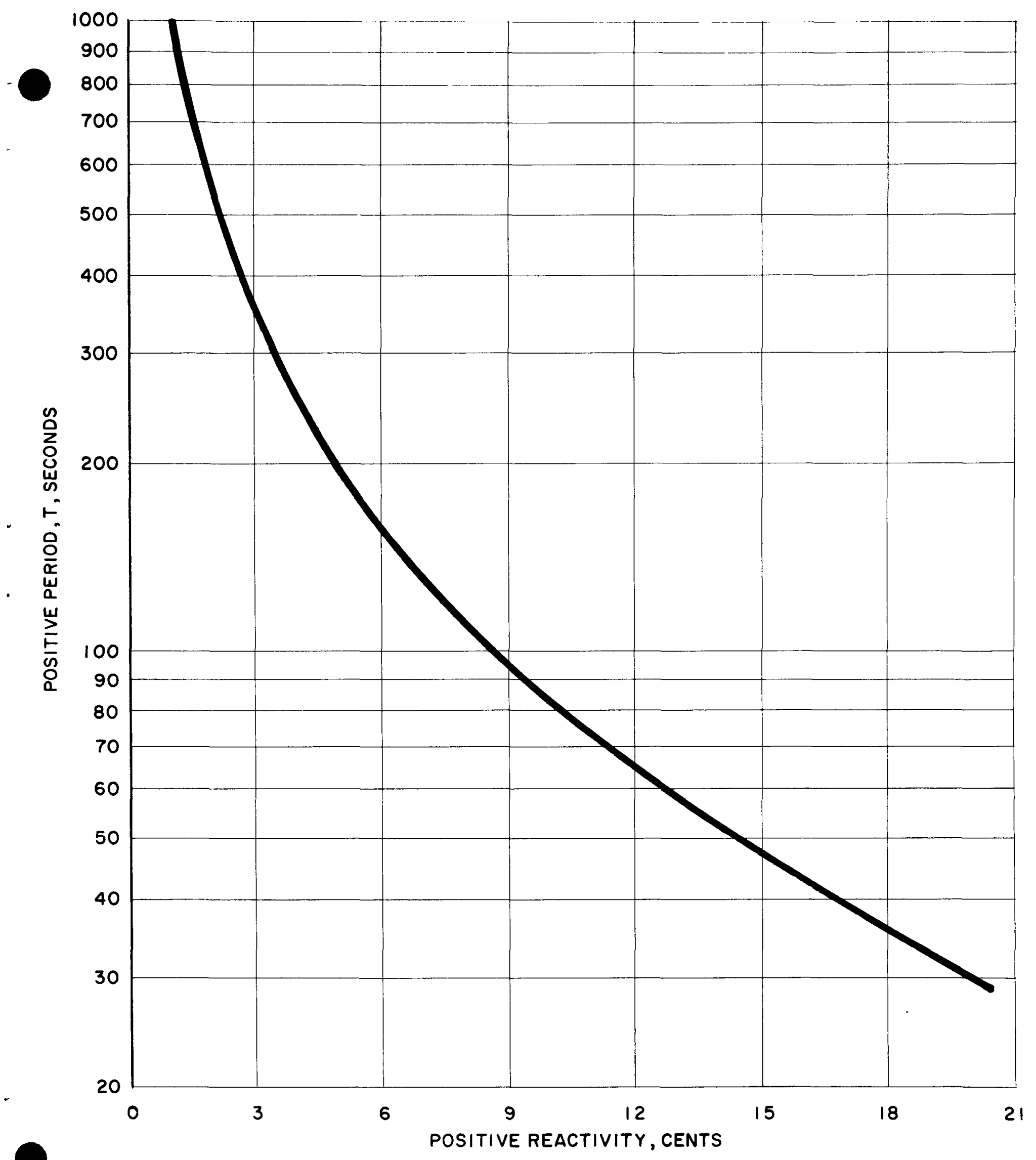

FIG. IO-REACTIVITY VERSUS REACTOR PERIOD 
where:

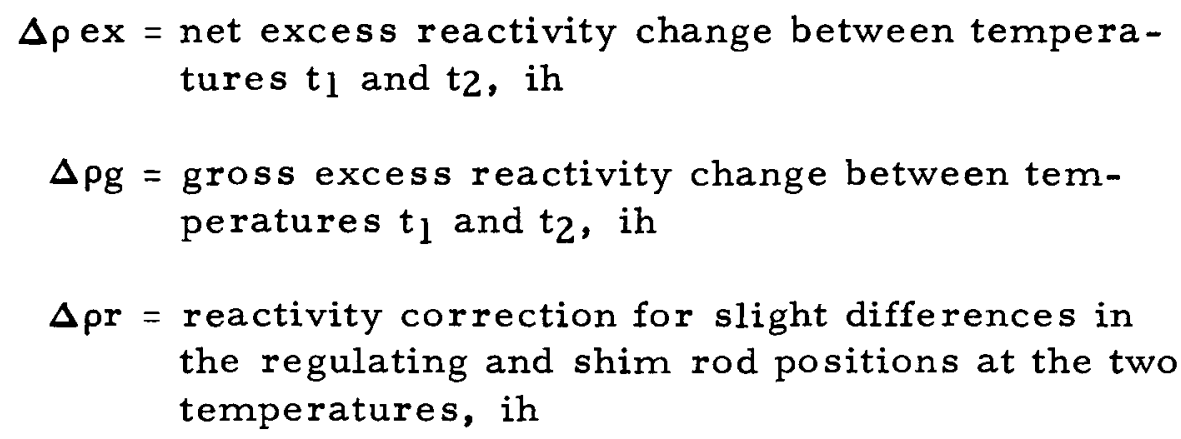

This was obtained by multiplying the slope of the rod calibration curve (Figures 8 and 9) in its operating region by the difference in rod position.
$\Delta \rho d=$ reactivity correction for power drift occuring during the base critical measurement at the higher temperature, $t_{l}$, ih.

The average value of the isothermal temperature coefficient in the temperature range $t_{1}$ to $t_{2}$ was then calculated using Equation (6). Table VII lists the values which were calculated from the one-period data obtained in the second and third sets of measurements using this method. The values in Table VII are based on the critical rod positions and oneperiod data given in Tables III and IV, Section IV, respectively.

A second period measurement technique, the two-period method was also used to determine the reactivity change with temperature. In this method, the reactivity effect of a temperature change was found by making period measurements at temperatures $t_{1}$ and $t_{2}$ with the control rods set at the same position in each case and comparing the two different periods obtained. The gross excess reactivity at each temperature for these rod positions was calculated from the period data using Equation (7) and the difference between the two reactivities gave the gross excess reactivity change between the two isothermal temperatures. This value was then corrected for slight differences in either the regulating or shim rod positions, if they existed, to obtain the net excess reactivity change. The isothermal temperature coefficient was calculated from Equation (6). The two-period technique was used only during the second set of temperature coefficient measurements between $500 \mathrm{~F}$ and $540 \mathrm{~F}$ (Table IV, Section IV). The calculated temperature coefficient values using this method are given in Table VIII. 
TABLE VII - ISOTHERMAL TEMPERATURE COEFFICIENTS FROM ONE-PERIOD DATA

\begin{tabular}{|c|c|c|c|c|c|c|c|c|c|c|}
\hline $\begin{array}{c}\text { Temper- } \\
\text { ature } \\
\text { Range, } \\
F \\
\end{array}$ & $\begin{array}{c}\text { Run No. } \\
\text { Compared } \\
\end{array}$ & $\begin{array}{l}\text { Temper- } \\
\text { ature, } t_{l} \text {, } \\
F \\
\end{array}$ & $\begin{array}{r}\text { Temper- } \\
\text { ature, } t_{2}, \\
F\end{array}$ & $\begin{array}{c}\text { Temper- } \\
\text { ature } \\
\text { Change, } \\
t_{2}-t_{1}, \\
F \\
\end{array}$ & $\begin{array}{c}\text { Average } \\
\text { Period, } \\
\text { T, } \\
\text { sec } \\
\end{array}$ & $\begin{array}{c}\text { Gross } \\
\text { Excess } \\
\text { Reac- } \\
\text { tivity } \\
\text { Change, } \\
\Delta \rho g, \\
\text { ih } \\
\end{array}$ & $\begin{array}{c}\text { Rod } \\
\text { Position } \\
\text { Reactivity } \\
\text { Correction, } \\
\Delta \rho r, \\
\text { ih } \\
\end{array}$ & $\begin{array}{c}\text { Power } \\
\text { Drift } \\
\text { Reac- } \\
\text { tivity } \\
\text { Cor- } \\
\text { rection, } \\
\Delta \rho d, \\
\text { ih } \\
\end{array}$ & $\begin{array}{c}\text { Net } \\
\text { Excess } \\
\text { Reac- } \\
\text { tivity } \\
\text { Change, } \\
\Delta \text { pex, } \\
\text { ih } \\
\end{array}$ & $\begin{array}{c}\text { Isothermal } \\
\text { Temperature } \\
\text { Coefficient } \\
\text { Between } \\
t_{1} \text { and } t_{2}, \\
\mathrm{ih} / \mathrm{F} \\
\end{array}$ \\
\hline $\begin{array}{c}540 \\
\text { to } \\
500\end{array}$ & $\begin{array}{l}65-4 \text { to } 67-5 \\
67-4 \text { to } 68-5 \\
65-4 \text { to } 68-6\end{array}$ & $\begin{array}{l}539.48 \\
519.92 \\
539.48\end{array}$ & $\begin{array}{l}519.98 \\
500.14 \\
500.36\end{array}$ & $\begin{array}{l}-19.50 \\
-19.78 \\
-39.12\end{array}$ & $\begin{array}{r}191.2 \\
177.9 \\
78.1\end{array}$ & $\begin{array}{l}16.25 \\
17.30 \\
33.61\end{array}$ & $\begin{array}{l}+0.08 \\
-0.24 \\
-0.16\end{array}$ & $\begin{array}{l}0 \\
0 \\
0\end{array}$ & $\begin{array}{l}16.33 \\
17.06 \\
33.45\end{array}$ & $\begin{array}{l}-0.8374 \\
-0.8625 \\
-0.8551\end{array}$ \\
\hline 600 & $\begin{array}{ll}101-4 & \text { to } 101-7 \\
101-4 & \text { to } 101-9 \\
101-4 & \text { to } 101-11 \\
101-4 & \text { to } 101-13 \\
101-5 & \text { to } 101-7 \\
101-5 & \text { to } 101-9 \\
101-5 & \text { to } 101-11 \\
101-5 & \text { to } 101-13\end{array}$ & $\begin{array}{l}599.52 \\
599.52 \\
599.52 \\
599.52 \\
599.56 \\
599.56 \\
599.56 \\
599.56\end{array}$ & $\begin{array}{l}561.41 \\
561.28 \\
560.56 \\
560.02 \\
561.41 \\
561.28 \\
560.56 \\
560.02\end{array}$ & $\begin{array}{l}-38.11 \\
-38.24 \\
-38.96 \\
-39.50 \\
-38.15 \\
-38.28 \\
-39.00 \\
-39.54\end{array}$ & $\begin{array}{l}79.9 \\
80.3 \\
78.0 \\
76.0 \\
79.9 \\
80.3 \\
78.0 \\
76.0\end{array}$ & $\begin{array}{l}33.04 \\
32.92 \\
33.66 \\
34.33 \\
33.04 \\
32.92 \\
33.66 \\
34.33\end{array}$ & $\begin{array}{c}-0.09 \\
+0.18 \\
-0.09 \\
-0.27 \\
0 \\
+0.27 \\
0 \\
-0.18\end{array}$ & $\begin{array}{l}+0.12 \\
+0.12 \\
+0.12 \\
+0.12 \\
0 \\
0 \\
0 \\
0\end{array}$ & $\begin{array}{l}33.07 \\
33.22 \\
33.69 \\
34.18 \\
33.04 \\
33.19 \\
33.66 \\
34.15\end{array}$ & $\begin{array}{l}-0.8678 \\
-0.8687 \\
-0.8647 \\
-0.8653 \\
-0.8661 \\
-0.8670 \\
-0.8631 \\
-0.8637\end{array}$ \\
\hline & $101-6$ to $102-5$ & 561.24 & 520.15 & -41.09 & 75.3 & 34.54 & -0.07 & 0 & 34.47 & -0.8389 \\
\hline 400 & $\begin{array}{l}101-6 \text { to } 102-6 \\
101-8 \text { to } 102-5 \\
101-8 \text { to } 102-6 \\
101-10 \text { to } 102-5 \\
101-10 \text { to } 102-6 \\
101-12 \text { to } 102-5 \\
101-12 \text { to } 102-6 \\
102-7 \text { to } 103-5 \\
102-7 \\
103-8 \text { to } 103-7 \\
103-8 \text { to } 105-5 \\
105-4 \text { to } 105-7 \\
105-4 \text { to } 106-5 \\
105-6 \text { to } 106-5 \\
105-6 \text { to } 106-7\end{array}$ & $\begin{array}{l}561.24 \\
561.34 \\
561.34 \\
560.72 \\
560.72 \\
560.17 \\
560.17 \\
519.98 \\
519.98 \\
480.58 \\
480.58 \\
440.90 \\
440.90 \\
441.18 \\
441.18\end{array}$ & $\begin{array}{l}520.17 \\
520.15 \\
520.17 \\
520.15 \\
520.17 \\
520.15 \\
520.17 \\
480.07 \\
480.38 \\
440.92 \\
441.34 \\
400.07 \\
400.07 \\
400.07 \\
400.07\end{array}$ & $\begin{array}{l}-41.07 \\
-41.19 \\
-41.17 \\
-40.57 \\
-40.55 \\
-40.02 \\
-40.00 \\
-39.91 \\
-39.600 \\
-39.66 \\
-39.24 \\
-40.83 \\
-40.83 \\
-41.11 \\
-41.11\end{array}$ & $\begin{array}{l}76.5 \\
75.3 \\
76.5 \\
75.3 \\
76.5 \\
75.3 \\
76.5 \\
77.0 \\
77.6 \\
78.3 \\
79.8 \\
76.9 \\
77.5 \\
76.9 \\
77.5\end{array}$ & $\begin{array}{l}34.16 \\
34.54 \\
34.16 \\
34.54 \\
34.16 \\
34.54 \\
34.16 \\
33.98 \\
33.79 \\
33.57 \\
33.09 \\
34.03 \\
33.82 \\
34.03 \\
33.82\end{array}$ & $\begin{array}{l}-0.07 \\
+0.15 \\
+0.15 \\
-0.51 \\
-0.51 \\
-1.06 \\
-1.06 \\
-0.42 \\
-0.53 \\
-0.24 \\
+0.11 \\
+0.45 \\
+0.45 \\
+0.71 \\
+0.71\end{array}$ & $\begin{array}{l}0 \\
0 \\
0 \\
0 \\
0 \\
0 \\
0 \\
0 \\
0 \\
0 \\
0 \\
0 \\
0 \\
0 \\
0\end{array}$ & $\begin{array}{l}34.09 \\
34.69 \\
34.31 \\
34.03 \\
33.65 \\
33.48 \\
33.10 \\
33.56 \\
33.26 \\
33.33 \\
33.20 \\
34.48 \\
34.27 \\
34.74 \\
34.53\end{array}$ & $\begin{array}{l}-0.8300 \\
-0.8422 \\
-0.8334 \\
-0.8388 \\
-0.8298 \\
-0.8366 \\
-0.8275 \\
-0.8409 \\
-0.8399 \\
-0.8404 \\
-0.8461 \\
-0.8445 \\
-0.8393 \\
-0.8450 \\
-0.8399\end{array}$ \\
\hline
\end{tabular}




\section{$\bullet$}

TABLE VIII - ISOTHERMAL TEMPERATURE COEFFICIENTS FROM TWO-PERIOD DATA

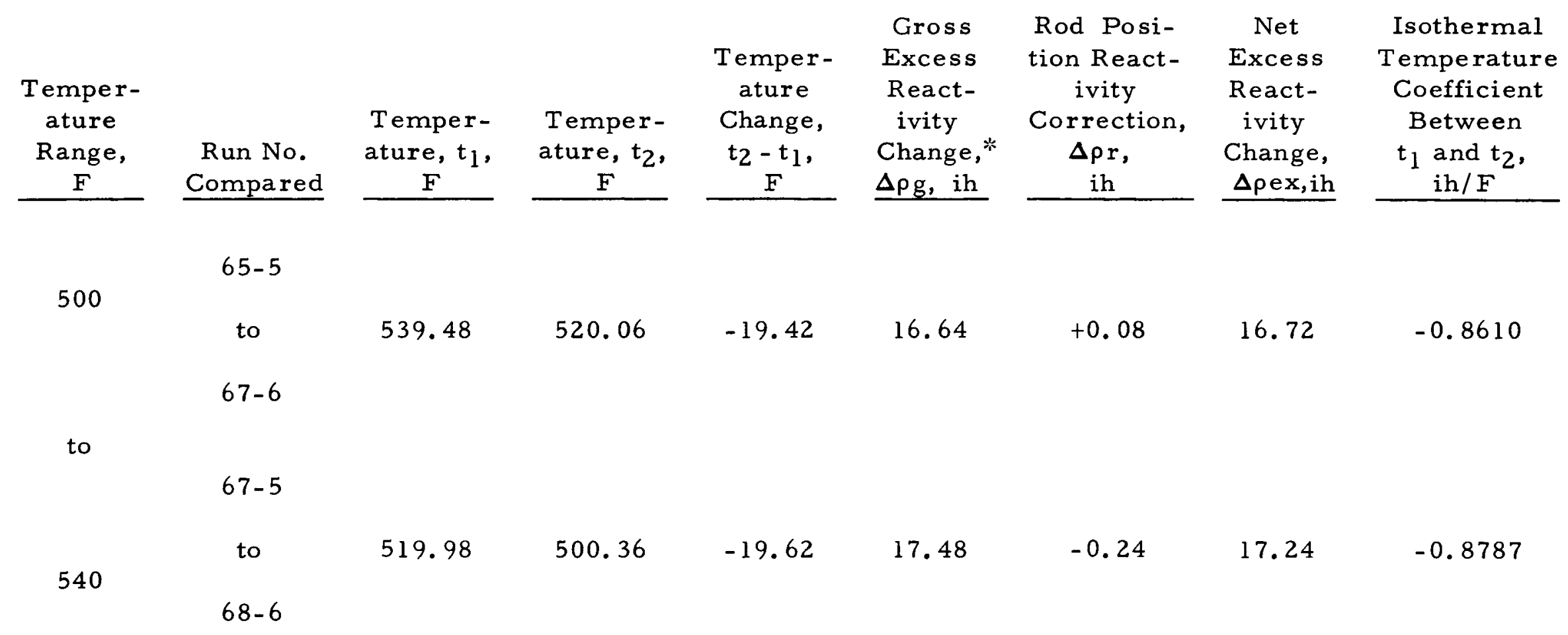




\section{Error Analysis}

The estimated standard errors of the critical rod and positive period reactivity measurements were computed from the estimated uncertainties in the basic experimental data. These estimates are as follows:

Rod Position Uncertainty - The control rod positions could be read to an estimated accuracy of \pm 0.03 inch. This corresponded to an uncertainty in reactivity of \pm 0.38 ih at the position of maximum slope on the rod worth curve.

Period Measurement Uncertainty - The period measurement accuracy was dependent on the length of period measured. This varied in the test. However, for the purpose of the error analysis, an estimated accuracy of \pm 2.5 per cent was assumed for the measurement of a typical 160-second period. This corresponded to an uncertainty of \pm 0.39 ih in excess reactivity determined from the period data.

Control Rod Calibration Curve Uncertainty - The uncertainty introduced by the use of the rod calibration curves was estimated to be $\pm 0.38 \mathrm{ih}$.

Temperature Measurement Uncertainty - The estimated accuracy to which the isothermal temperature could be read was $\pm 1 F$. This corresponded to a reactivity uncertainty of approximately \pm 0.9 ih in the temperature coefficient measurements.

The individual uncertainties in the experimental data above were combined in the following standard statistical formula to compute the estimated errors for the critical rod and positive period reactivity measurements:

$$
\sigma=\sqrt{\sum_{i} \sigma i^{2}}
$$

where

$$
\begin{aligned}
\sigma= & \text { the estimated standard measurement error, ih } \\
\sigma i= & \text { the estimated individual uncertainties in the reactivity } \\
& \text { measurement, ih }
\end{aligned}
$$

If th، same reactivity measurement was repeated $\mathrm{N}$ times, the standard error of the average of the measurements was the single measurement error value livided by the $\sqrt{\mathrm{N}}$. 
In the case of the temperature coefficient determinations from critical rod measurements, both the rod position and temperature uncertainties occurred twice, i.e., once at each of the two temperatures $t_{1}$ and $t_{2}$. A rod calibration curve uncertainty also existed. Therefore, the estimated error in $\Delta$ pex for a non-repeated critical rod measurement was:

$$
\begin{aligned}
\sigma(\text { critical }) & =\sqrt{2(0.38)^{2}+2(0.9)^{2}+(0.38)^{2}} \\
& = \pm 1.43 \mathrm{ih} .
\end{aligned}
$$

Similarly, the error associated with a period measurement determination of the temperature coefficient included two rod position and two temperature uncertainties, and one-period measurement uncertainty. Thus, the estimated error in $\Delta$ pex for nonrepeated period measurements was:

$$
\begin{aligned}
\sigma(\text { period }) & =\sqrt{2(0.38)^{2}+2(0.9)^{2}+(0.39)^{2}} \\
& = \pm 1.44 \mathrm{ih} .
\end{aligned}
$$

The errors in the experimental temperature coefficient values were then found by dividing the above errors by the temperature interval over which the measurements were made.

\section{B. DETERMINATION OF THE GROWTH OF THE CONTROL ROD EXTENSIONS}

To determine the growth of the control rod extensions with temperature, the rods were fully inserted at the beginning of the third set of measurements and a reference mark was established on each extension at an isothermal reactor temperature of $600 \mathrm{~F}$. At the end of the set of measurements, when the temperature had been reduced to $400 \mathrm{~F}$, the control rods were again fully inserted and the change in elevation of each reference mark was measured. The measurements were repeated twelve times for each operating control rod, and the average of the twelve measurements was used to obtain the growth of the rod extensions.

The results of the measurements indicated a net growth for each extension of approximately 0.060 of an inch for the $200 \mathrm{~F}$ temperature change from $400 \mathrm{~F}$ to $600 \mathrm{~F}$. Based on this result, the expansion coefficient of the rod extensions is $0.0003 \mathrm{in} . / \mathrm{F}$. The effect of this growth on the rod calibration curves was not factored into the temperature coefficient calculations for two reasons; ( 1 ) it is a small correction amounting to about $0.004 \mathrm{ih} / \mathrm{F}$ with the rods located at the position of maximum slope on their worth curves, and (2) the growth was measured with the rods fully inserted with the maximum length of the extensions exposed to the high temperatures, whereas during the temperature coefficient measurements the control rods were located at intermediate positions of withdrawal. 


\section{A. AVERAGE ISOTHERMAL TEMPERATURE COEFFICIENT VALUES}

The temperature coefficient values found by the various experimental techniques (Tables V, VII, and VIII) were averaged to obtain an average isothermal temperature coefficient for each temperature interval investigated in the test. All values were given equal weight regardless of the measureing technique used to obtain the value. These data are summarized in Table IX below.

TABLE IX - VALUES OF THE AVERAGE ISOTHERMAL TEMPERATURE COEFFICIENTS

\begin{tabular}{|c|c|c|c|}
\hline $\begin{array}{c}\text { Measure- } \\
\text { ment No., } \\
\mathrm{n}\end{array}$ & $\begin{array}{c}\text { Nominal } \\
\text { Temperature } \\
\text { Range, } \\
\mathrm{F} \\
\end{array}$ & $\begin{array}{c}\text { Average } \\
\text { Temperature } \\
\text { Coefficient, } \\
\mathrm{ih} / \mathrm{F} \\
\end{array}$ & $\begin{array}{c}\text { Estimated } \\
\text { Standard } \\
\text { Error, } \sigma n, \\
\text { ih/F } \\
\end{array}$ \\
\hline 1 & $400-440$ & -0.8436 & \pm 0.0127 \\
\hline 2 & $440-480$ & -0.8453 & \pm 0.0179 \\
\hline 3 & $480-520$ & -0.8492 & \pm 0.0179 \\
\hline 4 & $500-520$ & -0.8498 & 玉0.0414 \\
\hline 5 & $500-540$ & -0.8326 & \pm 0.0253 \\
\hline 6 & $520-540$ & -0.8388 & \pm 0.0414 \\
\hline 7 & $520-560$ & -0.8474 & \pm 0.0104 \\
\hline 8 & $560-600$ & -0.8665 & \pm 0.0090 \\
\hline
\end{tabular}

The estimated errors shown in Table IX for the average temperature coefficients were calculated using the reactivity errors for single critical and period measurements given by Equations (10) and (11). Since both errors are the same, the errors in the average temperature coefficients could be obtained by dividing the single measurement error by the temperature interval over which the measurement was made and reducing this value by the square root of the number of times the measurement was repeated. As seen in Table IX, the estimated errors vary considerably with the temperature range. The variation occurs because in some cases the temperature intervals are different and because some measurements were repeated more times than others. The estimated standard error, $\bar{\sigma}$, for all the measurements listed in Table IX is: 


$$
\bar{\sigma}=\sqrt{\frac{\sum_{\mathrm{n}}^{\sigma_{\mathrm{n}}^{2}}}{\mathrm{~N}}}= \pm 0.0251 \mathrm{ih} / \mathrm{F}
$$

where:

$$
\begin{aligned}
& n=\text { the number of the measurement }(n=1 \text { to } 8) \\
& \sigma \mathrm{n}=\text { the estimated standard error for the } \mathrm{n}^{\text {th }} \text { measure- } \\
& \text { ment, ih/F } \\
& N=\text { the total number of measurements made }(N=8)
\end{aligned}
$$

\section{B. EXPERIMENTAL EQUATION FOR THE ISOTHERMAL TEMPERATURE COEFFICIENT}

The predicted temperature dependence of the isothermal temperature coefficient over the temperature range $400 \mathrm{~F}$ to $600 \mathrm{~F}$ is given in Section II, $\mathrm{C}$ by Equation (2). As indicated below, it is the standard equation for a straight line.

$$
y=a+b(t-500)
$$

where:

$y=$ the predicted isothermal temperature coefficient as a function of temperature, ih/F

$\mathrm{a}=$ the predicted isothermal temperature coefficient value at the reference temperature $500 \mathrm{~F},-0.912 \mathrm{ih} / \mathrm{F}$

$\mathrm{b}=$ the predicted slope of the straight line, $-2.65 \times 10^{-4} \mathrm{ih} / \mathrm{F}^{2}$

$t=$ the isothermal temperature, $F$

The experimental data given in Table IX were used to obtain an equation analogous to Equation (13). A least square fit of the data was made by solving the two normal equations given below for the constants $a$ and $b$ :

$$
\begin{aligned}
& a N+b \sum_{n}(t-500)_{n}=\sum_{n} y_{\operatorname{exper}_{n}} \\
& a \sum_{n}(t-500)_{n}+b \sum_{n}(t-500)_{n}^{2}=\sum_{n} y_{\operatorname{exper}_{n}}(t-500)_{n}
\end{aligned}
$$


where:

$$
\begin{aligned}
& a=\text { the temperature coefficient value at } 500 \mathrm{~F} \text { from the least } \\
& \text { square fit of the experimental data, ih/F } \\
& b=\text { the slope of the straight line fit to the experimental data, } \\
& \text { ih/ } / \mathrm{F}^{2} \\
& \mathrm{n}=\text { the measurements over the different temperature ranges } \\
& (\mathrm{n}=1 \text { to } 8) \\
& \mathrm{y}_{\text {exper }}=\text { the experimental value of the isothermal temperature coef- } \\
& \text { ficient for the } n^{\text {th }} \text { measurement, ih/F } \\
& \mathrm{N}=\text { the total number of measurements made }(\mathrm{N}=8) \\
& \mathrm{t}=\text { the average isothermal temperature of the measurement, } \\
& F \text {, i. e., the midpoint of the nominal temperature range } \\
& \text { over which the measurement was made. }
\end{aligned}
$$

\begin{tabular}{|c|c|c|c|c|c|}
\hline $\begin{array}{c}\text { Measure- } \\
\text { ment No., } \\
n\end{array}$ & $\begin{array}{c}\text { Average } \\
\text { Temper- } \\
\text { ature, } t, \\
F\end{array}$ & $\begin{array}{c}(t-500) \\
F \\
\end{array}$ & $\begin{array}{l}\text { Yexper } \\
\text { ih/F } \\
\end{array}$ & $\begin{array}{c}(t-500)^{2} \\
F^{2} \\
\end{array}$ & $\begin{array}{c}\left(y_{\text {exper }}\right)(t-500) \\
\text { ih }\end{array}$ \\
\hline 1 & 420 & -80 & -0.8436 & 6400 & +67.488 \\
\hline 2 & 460 & -40 & -0.8453 & 1600 & +33.812 \\
\hline 3 & 500 & 0 & -0.8492 & 0 & 0 \\
\hline 4 & 510 & +10 & -0.8498 & 100 & -8.498 \\
\hline 5 & 520 & +20 & -0.8326 & 400 & -16.652 \\
\hline 6 & 530 & +30 & -0.8388 & 900 & -25.164 \\
\hline 7 & 540 & +40 & -0.8474 & 1600 & -33.900 \\
\hline \multirow[t]{2}{*}{8} & 580 & +80 & -0.8665 & 6400 & -69.320 \\
\hline & & +60 & -6.7733 & $+17,400$ & -52.234 \\
\hline
\end{tabular}

The data used in the least square fit are given in Table $\mathrm{X}$.

\section{TABLE X - LEAST SQUARE DATA}

If the above numbers are substituted in Equations (14) and (15), and the equations are solved for the coefficients $a$ and $b$, one obtains:

$$
\begin{gathered}
8 a+60 b=-6.7733 \\
60 a+17,400 b=-52.234
\end{gathered}
$$




$$
\text { or } \begin{aligned}
a & =-0.8460 \mathrm{ih} / \mathrm{F} \\
\mathrm{b} & =-0.846 \times 10^{-4} \mathrm{ih} / \mathrm{F}^{2}
\end{aligned}
$$

Therefore, the form of Equation (13) calculated from the experimental data is:

$$
\mathrm{y}_{\text {calc }}=-0.8460+\left(-0.846 \times 10^{-4}\right)(\mathrm{t}-500) \mathrm{ih} / \mathrm{F}
$$

Figure 11 shows both the variation of the isothermal temperature coefficient between $400 \mathrm{~F}$ and $600 \mathrm{~F}$ given by Equation(18) and the experimental data on which the equation is based (Table IX). Also shown in Figure 11 is the predicted value of the temperature coefficient over this temperature range (Equation (13)).

\section{STANDARD ERROR OF THE MEASUREMENTS FROM THE EXPERIMENTAL DATA}

The estimated standard error, $\bar{\sigma}$, of all the measurements based on the assumed uncertainties in the basic measurements, is given by Equation (12) in Section VI, A. The actual standard error, $\bar{\sigma}$ exper, of the measurements based on the experimental data may be found by evaluating the residuals of the measurements and using the following equation:

$$
\bar{\sigma}_{\text {exper }}=\sqrt{\frac{\sum_{n} R_{n}^{2}}{N}}
$$

where:

$$
\begin{aligned}
& \mathrm{n}=\text { the measurements over the different temperature ranges } \\
& \quad(\mathrm{n}=1 \text { to } 8)
\end{aligned}
$$

The residual, $R_{n}$, is equal to the difference between the calculated temperature coefficient for the $n^{\text {th }}$ measurement, based on the least square fit of the experimental data (Equation(18)), and the actual experimental value (Table IX),

$$
\mathrm{R}_{\mathrm{n}}=\mathrm{y}_{\mathrm{calc}_{\mathrm{n}}}-\mathrm{y}_{\text {exper }} \mathrm{n}
$$

The parameters for Equations (19) and (20) are listed in Table XI. 


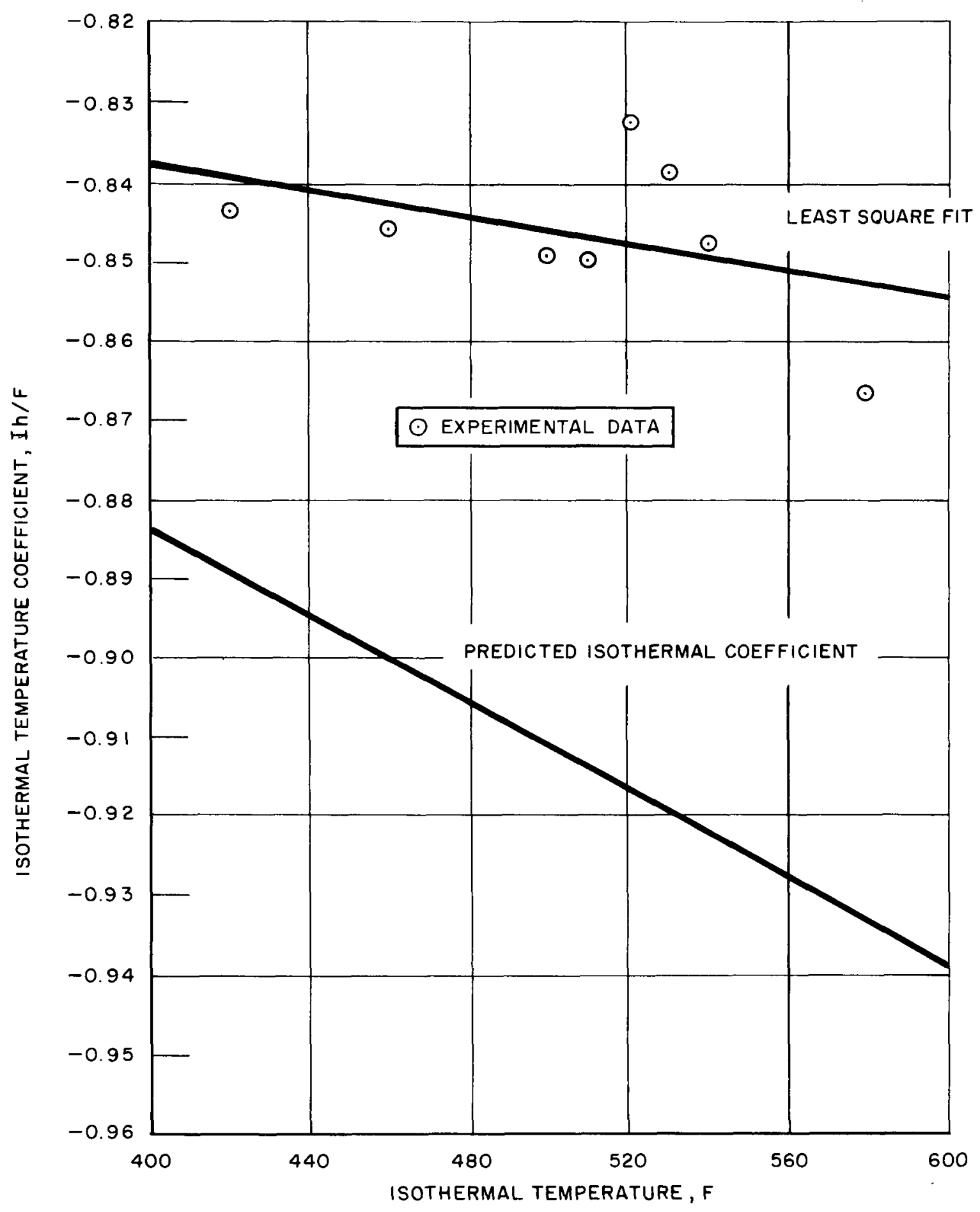

FIG.|I-ISOTHERMAL TEMPERATURE COEFFICIENT VERSUS TEMPERATURE 


\section{TABLE XI - STANDARD ERROR TABULATION}

\begin{tabular}{|c|c|c|c|c|c|}
\hline $\begin{array}{l}\text { Measure- } \\
\text { ment No., } \\
\text { n }\end{array}$ & $\begin{array}{c}\text { Average } \\
\text { Temper - } \\
\text { ature, } t \text {, } \\
F\end{array}$ & $\begin{array}{l}\text { Ycalc, } \\
\mathrm{ih} / \mathrm{F}\end{array}$ & $\begin{array}{l}\text { Yexper, } \\
\text { ihfF }\end{array}$ & $\begin{array}{c}R_{n,} \\
i h / F\end{array}$ & $\begin{array}{c}\mathrm{R}_{\mathrm{n}}^{2} \\
(\mathrm{ih} / \mathrm{F})^{2}\end{array}$ \\
\hline 1 & 420 & -0.8392 & -0.8436 & +0.0044 & $19.36 \times 10^{-6}$ \\
\hline 2 & 460 & -0.8426 & -0.8453 & +0.0027 & $7.29 \times 10^{-6}$ \\
\hline 3 & 500 & -0.8460 & -0.8492 & +0.0032 & $10.24 \times 10^{-6}$ \\
\hline 4 & 510 & -0.8468 & -0.8498 & +0.0030 & $9.00 \times 10^{-6}$ \\
\hline 5 & 520 & -0.8477 & -0.8326 & -0.0151 & $228.01 \times 10^{-6}$ \\
\hline 6 & 530 & -0.8485 & -0.8388 & -0.0097 & $94.09 \times 10^{-6}$ \\
\hline 7 & 540 & -0.8494 & -0.8474 & -0.0020 & $4.00 \times 10^{-6}$ \\
\hline 8 & 580 & -0.8528 & -0.8665 & +0.0137 & $187.69 \times 10^{-6}$ \\
\hline
\end{tabular}

Based on these data, the actual standard error of the measurements, as determined by Equation (19), is $\pm 8.37 \times 10-3 \mathrm{ih} / \mathrm{F}$. When this error is compared with the estimated error, $\pm 25.1 \times 10^{-3} \mathrm{ih} / \mathrm{F},{ }^{*}$ it appears that the errors assumed for the basic measurements** were too large. The difference is probably due to the fact that the average isothermal temperature, the largest uncertainty in the measurement, could be determined with greater accuracy than originally assumed ( \pm 1 F) since the experimental values were an average of six temperature sensor readings.

\footnotetext{
* Section VI, A

$* *$ Section V, A
} 


\section{CONCLUSIONS}

A comparison of the measured and predicted values of the isothermal temperature coefficient of reactivity for the Enrico Fermi reactor shows that there is satisfactory agreement over the temperature range $400 \mathrm{~F}$ to $600 \mathrm{~F}$. In this range, the measured values average about 7 per cent less than the predicted values. The difference is less than might be expected considering the complexity of the calculations involved in obtaining the predicted values. Preliminary studies indicate that the discrepancy which does exist is primarily due to an overestimate of the core radial expansion component of the temperature coefficient which resulted from an inaccurately predicted radial fuel worth distribution. Nevertheless, on the basis of the good overall agreement found, it can be concluded that the method which was used for the calculation of temperature-reactivity feedback in the reactor is probably accurate. This gives reason for optimism that the calculated power coefficients will also be sufficiently accurate. Thus it would appear that the excess reactivity allowances for temperature override in the reactor design a re probably adequate.

The agreement between the measured and predicted slope of the isothermal temperature coefficient variation with temperature is not as good as the agreement between the absolute values. The predicted slope is approximately three times larger than the slope actually measured. However, it is not too surprising that the slopes differ by this much since they are a measure of a small second order effect, i. e., an effect which is so small that it could not be determined accurately from the experimental data. Another reason for the discrepancy between the values of the slope was that the calculation of the predicted slope depended on knowledge of the variation of the material the rmal expansion coefficients with temperature and these data are not accurately known.

The results of the measurements of the growth of the operating control rod extensions with temperature show that the effect of temperature on the rod calibration curves is negligible. 


\section{REFERENCES}

1. PRDC, "Enrico Fermi Hazard Summary Report and Technical Information", Volumes 1 through 9, as amended in March 1964.

2. R. B. Nicholson, "The Doppler Effect in Fast Neutron Reactors", APDA$139,1960$.

3. R. E. Horne, "Enrico Fermi Nuclear Test Procedure No. 2, Absolute Power Calibration", APDA, 1963.

4. H. A. Wilber, "Enrico Fermi Nuclear Test Procedure No. 10, Preliminary Isothermal Temperature Coefficient", APDA, 1962.

5. H. A. Wilber, "Enrico Fermi Nuclear Test Procedure No. 15, Isothermal Temperature Coefficient", APDA, 1962.

6. R. E. Mueller, C. E. Branyan, and J. B. Nims, "Initial Loading to Criticality of the Enrico Fermi Reactor", APDA-NTS-1, 1964.

7. R. E. Mueller, S. K. Kapil, and H. A. Wilber, "Preliminary Evaluation of Nuclear Test Procedure No. 5, Flow Dependence of Reactivity", APDA Internal Memorandum, P-63-365, 1963.

8. PRDC, "Power Reactor Development Company, Enrico Fermi Atomic Power Plant, Preoperational Test Report XIV-D. 1, Calibration of Temperature Instrumentation for Nuclear Test Program", July 1963.

9. B. M. Segal and C. E. Branyan, "Neutron Source Effects", to be published. 